\title{
Wave-current interactions in a wind-jet region
}

\author{
Laura Ràfols $^{1,2}$, Manel Grifoll ${ }^{1}$, and Manuel Espino ${ }^{1}$ \\ ${ }^{1}$ Maritime Engineering Laboratory (LIM-UPC), Polytechnic University of Catalonia (BarcelonaTech), \\ C/Jordi Girona 1-3 Edif. D1, 08034 Barcelona, Spain \\ ${ }^{2}$ Meteorological Service of Catalonia (SMC), C/Berlin 38-48 4a, 08029 Barcelona, Spain
}

Correspondence: Laura Ràfols (laura.rafols@upc.edu)

Received: 2 September 2018 - Discussion started: 4 October 2018

Revised: 3 December 2018 - Accepted: 10 December 2018 - Published: 7 January 2019

\begin{abstract}
Wave-current interactions (WCIs) are investigated. The study area is located at the northern margin of the Ebro shelf (northwestern Mediterranean Sea), where episodes of strong cross-shelf wind (wind jets) occur. The aim of this study is to validate the implemented coupled system and investigate the impact of WCIs on the hydrodynamics of a wind-jet region. The Coupled Ocean-AtmosphereWave-Sediment Transport (COAWST) modeling system, which uses the Regional Ocean Model System (ROMS) and Simulating WAves Nearshore (SWAN) models, is used in a high-resolution domain $(350 \mathrm{~m})$. Results from uncoupled numerical models are compared with a two-way coupling simulation. The results do not show substantial differences in the water current field between the coupled and the uncoupled runs. The main effect observed when the models are coupled is in the water column stratification, due to the turbulent kinetic energy injection and the enhanced surface stress, leading to a larger mixed-layer depth. Regarding the effects on the wave fields, the comparison between the coupled and the uncoupled runs shows that, when the models are coupled, the agreement of the modeled wave period significantly improves and the wave energy (and thus the significant wave height) decreases when the current flows in the same direction as the waves propagate.
\end{abstract}

Copyright statement. The works published in this journal are distributed under the Creative Commons Attribution 4.0 License. This licence does not affect the Crown copyright work, which is reusable under the Open Government Licence (OGL). The Creative Commons Attribution 4.0 License and the OGL are interoperable and do not conflict with, reduce or limit each other.

\section{Introduction}

During the last decade, several water circulation models have been developed, including the wind-wave-induced currents. There are two different formulations to include the so-called wave effects on currents (WECs) in the three-dimensional primitive equations: by means of the radiation-stress gradient (Mellor, 2011) and with the vortex force (VF) formalism (Uchiyama et al., 2010; Kumar et al., 2012). The VF formalism separates the conservative and non-conservative contributions in the momentum balance equations, which allows one to evaluate flow fields within both inner shelf and surf zone environments (Kumar et al., 2012).

From a modeling perspective, several circulation and wave models have been coupled in order to consider the wavecurrent interactions (WCIs). For instance, Xie et al. (2001) coupled a 3-D ocean model (Princeton Ocean Model, POM) with the WAM wave model and found that wind waves can significantly affect coastal ocean currents both at the surface and near the seabed. Osuna and Wolf (2005) implemented the coupling between the circulation Proudman Oceanographic Laboratory Coastal Ocean Modeling System (POLCOMS) and the WAM model in the Irish Sea. This system was then modified by Bolaños et al. (2011), who included threedimensional interactions following Mellor $(2003,2005)$ and applied the coupled model system to the Mediterranean Sea. Tang et al. (2007) implemented the WCI in a 3-D ocean model (POM) and a spectral wave model (WAVEWATCH III), based on the Jenkins (1987) formulation, and evaluated the model by comparison with surface velocity data derived from surface drifters. McWilliams et al. (2004) developed a multi-scale asymptotic theory for the evolution and interaction of currents and surface gravity waves of finite 
depth, which was then implemented and extended for applications within the surf zone in the UCLA ROMS model by Uchiyama et al. (2010). Warner et al. (2008b) used the Model Coupling Toolkit (MCT) to couple the ocean circulation Regional Ocean Model System (ROMS) and the surface wave model Simulating WAves Nearshore (SWAN) and included nearshore processes, such as radiation-stress terms based on Mellor $(2003,2005)$ and a surface roller model (Svendsen, 1984; Svendsen et al., 2002). This system was then further developed by Warner et al. (2010) to include one-way grid refinement in the oceanic and wave models, coupling to an atmospheric model in order to include effects of sea surface temperature and waves, and to provide interpolation mechanisms to allow the models to compute on different grids. The resulting system is known as the Coupled Ocean-Atmosphere-Wave-Sediment Transport (COAWST) modeling system. Then, Kumar et al. (2012) implemented the VF formalism into the COAWST modeling system, with some modifications to the method of Uchiyama et al. (2010).

Previous studies have analyzed the physical processes involved in the WCIs and the relevance of the coupling effects can vary depending, mainly, on the water depth and the energy of the studied event. The WCIs have demonstrated to be important in coastal regions (Wolf and Prandle, 1999; Kumar et al., 2012; Liang et al., 2017) and estuaries (Olabarrieta et al., 2011; Bolaños et al., 2014), and during energetic events such as hurricanes or strong wind events (Xie et al., 2008; Sheng et al., 2010; Renault et al., 2012; Benetazzo et al., 2013). As a matter of fact, the previous cited studies have different focuses and are applied to different domain types (going from seas to surf zones and estuaries), and thus the grid resolutions used in these studies varies from a few meters to a few kilometers. For instance, Osuna and Wolf (2005) studied the coupling effects in the Irish Sea, Benetazzo et al. (2013) analyzed the WCI in a semi-enclosed basin with particular focus on events associated with prevailing and dominant winds of the region, and Kumar et al. (2012) applied different WCI tests in coastal regions, including the study of obliquely incident waves on a planar beach and the analysis of the wave-induced cross-shore flows in the inner shelf.

The north Ebro shelf (northwestern Mediterranean Sea) is a region characterized by northwestern (NW) winds that are channeled through the Ebro Valley and which result in cross-shelf wind jets when they reach the sea. This region is very interesting from a meteo-oceanographic point of view because multiple processes take place, such as bimodal wave spectra and the development of a two-layer cross-shelf flow. Some authors have investigated the circulation patterns (Grifoll et al., 2015; Ràfols et al., 2017a) and the wave field (Bolaños-Sanchez et al., 2007; Grifoll et al., 2016; Ràfols et al., 2017b) during these NW wind-jet events but less efforts have been made to investigate the WCI in the region. Due to the limited observational data, in order to study the wind-jet-induced dynamics of the region, the use of numerical models is required. However, at the same time, this makes the investigation rather challenging and forces a rather qualitative analysis based on the modeled physical processes' reliability. The purpose of this study is to validate the implemented coupled system and investigate the coupling effects on the circulation and the wave field at the continental shelf during a wind-jet event. With this aim, results from uncoupled models are compared with the outputs from a two-way coupled numerical model. The selected study period is from 15 March to 15 May 2014 because it contains four wind-jet episodes. Additionally, this period has previously been used to validate numerical models in the study region, and the wind-wave characterization (Ràfols et al., 2017b) and water shelf circulation (Ràfols et al., 2017a) were investigated by combining numerical efforts and in situ observations.

This work is organized as follows. In Sect. 2, the study area and the methods used in this work are presented. The results are shown in Sect. 3, discerning between the coupling effects on currents and the coupling effects on waves. A discussion of the results can be found in Sect. 4, and the main conclusions of the work are highlighted in Sect. 5.

\section{Study area and methodology}

\subsection{Study area}

The north Ebro shelf is located at the southern part of the Catalan coast, at $40.4-41.1^{\circ} \mathrm{N}$ and $0.4-1.3^{\circ} \mathrm{E}$ (see Fig. 1). The shelf of this region is characterized by the transition from a narrow shelf $(\sim 10 \mathrm{~km})$ at its northern margin to a broader shelf $(\sim 60 \mathrm{~km})$ towards the south.

The most characteristic wind of the region is the northwesterly wind (mistral), which is channeled through the Ebro Valley resulting in a cross-shelf wind jet when it reaches the sea. This wind jet is related to the presence of a highpressure area over the Iberian Peninsula and a low-pressure area over the Mediterranean Sea. Thus, it is more common during autumn and winter (Grifoll et al., 2015), when large atmospheric pressure gradients occur. The predominant regional current is the quasi-permanent slope current known as the Northern Current, which is an entity flowing along the continental slope (Millot, 1999) that can be modified by mesoscale events such as current meandering or eddies (Font et al., 1995). The water circulation in the inner and middle shelf presents strong temporal and spatial variability due to the strong gradients in the bathymetry and wind field associated with wind-jet episodes (Grifoll et al., 2015; Ràfols et al., 2017a). The wave climate at the Ebro Delta is characterized by the predominance of NW waves (which coincides with the predominance of NW winds), although there are also significant storms from the east and south. These storms tend to develop a bimodal directional spectrum due to the coexistence of wind waves and swell waves (Sánchez-Arcilla et al., 2008; Ràfols et al., 2017b). Local wind waves (sea system) show a broadband spectrum with a high variety of frequencies asso- 
ciated with irregular sea states. In contrast, waves generated far away (swell system) present a narrowband spectrum with a frequency range with less associated energy. Then, when the sea and swell systems exist at the same time, bimodal spectra occur (Ràfols et al., 2017b).

\subsection{Data}

For validation purposes, oceanographic and coastal meteorological measurements from Puertos del Estado (http://www. puertos.es, last access: 6 March 2018) are used. Specifically, data were obtained from a coastal wave buoy, a deepwater buoy and high-frequency (HF) radar. The locations are shown in Fig. 1, jointly with the bathymetry and the numerical domains.

The coastal wave buoy (CB) is a TRIAXYS buoy located at $41.07^{\circ} \mathrm{N}, 1.19^{\circ} \mathrm{E}$, at $15 \mathrm{~m}$ depth, deployed in November 1992. It provides significant wave height, peak period, nautical direction and directional wave spectra, among other data. The deep-water buoy (DB), an ocean Seawatch buoy located at $40.68^{\circ} \mathrm{N}, 1.47^{\circ} \mathrm{E}$, at $688 \mathrm{~m}$ depth, was deployed in August 2004. This buoy measures water velocity and water temperature at the subsurface (nominal depth of $3 \mathrm{~m}$ ), wind vectors at $3 \mathrm{~m}$ above the sea surface, significant wave height, peak period, nautical direction and directional wave spectra, among other parameters. In order to be able to compare the measured wind data at $3 \mathrm{~m}$ height with the modeled data at $10 \mathrm{~m}$ height, the modeled data have been extrapolated from 10 to $3 \mathrm{~m}$ using a logarithmic profile (see Appendix A).

The HF radar system used in this work is a CODAR SeaSonde standard-range system composed of three remote shelf-based sites that became operational in December 2013. Each site comprises a transmitter-receiver antenna that operates at a nominal frequency of $13.5 \mathrm{MHz}$ with a $90 \mathrm{kHz}$ bandwidth. The system provides hourly measurements of the current velocities in the top meter of the water column with a horizontal resolution of $3 \mathrm{~km}$ and a cutoff filter of $100 \mathrm{~cm} \mathrm{~s}^{-1}$. More information about the system is available in Lorente et al. (2015).

\subsection{Numerical models}

\subsubsection{COAWST modeling system description}

The COAWST Modeling System (Warner et al., 2010) has been widely used by many authors to investigate the WCI (Olabarrieta et al., 2011; Renault et al., 2012; Benetazzo et al., 2013; Rong et al., 2014; Grifoll et al., 2014; Bruneau and Toumi, 2016, among others). In this study, the COAWST modeling system is used to perform the uncoupled ROMS and SWAN model simulations and a model run with two-way coupling.

The SWAN model is a third-generation numerical wave model that computes random, short-crested waves in coastal regions with shallow water and ambient currents (Booij et al.,
1999). It is based on the action balance equation in terms of action density (Bretherton and Garrett, 1968) with sources and sinks, and incorporates state-of-the-art formulations of wave-wave interactions and the processes of wave generation and dissipation.

The ROMS model is a split-explicit, free-surface, terrainfollowing, primitive equation oceanic model that solves the 3-D Reynolds-averaged Navier-Stokes equations using the hydrostatic and Boussinesq assumptions (Shchepetkin and McWilliams, 2005; Haidvogel et al., 2008). The model uses finite-difference approximations on a terrain-following vertical coordinate (sigma coordinate) and on a horizontal curvilinear Arakawa-C grid.

The Model Coupling Toolkit (MCT; Larson et al., 2004; Jacob et al., 2004) is a Fortran90 program that works with the MPI protocol. It allows the transmission and transformation of various distributed data between component models using a parallel coupled approach. When the models are initialized, each model decomposes its own domain into different sections, which are distributed to processors. On each processor, each grid section initializes into MCT and a global map of the distribution of the segments is computed. Each segment also initializes an attribute vector that contains the fields to be exchanged and establishes a router to provide an exchange pathway between model components. While the simulation is run, the models reach a synchronization point, fill the attribute vectors with data and exchange fields. Further details are described in Warner et al. (2008a).

\subsubsection{System setup}

Three different runs have been performed in this work (see Fig. 2): one with the ROMS model uncoupled (uncR), one with the SWAN model uncoupled (uncS) and, finally, one with the ROMS and SWAN models two-way coupled $(c R S)$.

The numerical domain has a horizontal resolution of $350 \mathrm{~m}$ and, in the ROMS case, a vertical resolution of $20 \sigma$ levels. The bathymetry introduced in the models has a grid resolution of $0.0083^{\circ}$ and was obtained from the General Bathymetric Chart of the Oceans (GEBCO; https://www.gebco.net, last access: 10 April 2016). Both SWAN and ROMS models are forced with hourly atmospheric data from a previous WRF (Weather Research and Forecasting) model run provided by the SMC (Servei Meteorològic de Catalunya) that has a spatial resolution of $3 \mathrm{~km}$.

In order to generate the boundary conditions for the SWAN model, a downscaling technique has been used. The entire system consists of three nested domains (see Fig. 1a). The largest one covers the western Mediterranean Sea with a spatial resolution of $15 \mathrm{~km}$ and provides boundary conditions to a second-level domain. The latter covers the Balearic Sea with a spatial resolution of $3 \mathrm{~km}$ and provides boundary conditions to the smaller domain, which has a horizontal resolution of $350 \mathrm{~m}$. This study is focused on this last domain. The nesting between each domain consists of providing the 
(a)

(b)
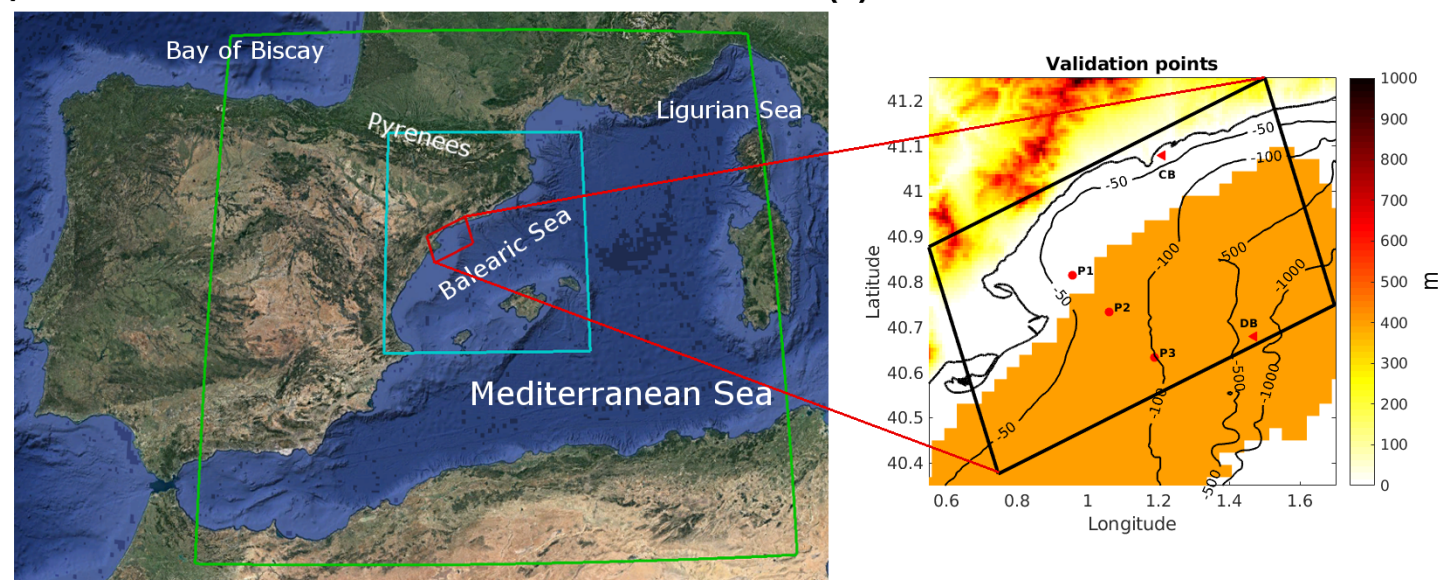

Figure 1. Study area. (a) NW Mediterranean Sea and numerical domains: $15 \mathrm{~km}$ resolution domain for the SWAN model (green), $3 \mathrm{~km}$ resolution domain for the SWAN model (blue) and $350 \mathrm{~m}$ resolution coastal domain for the ROMS and SWAN models (red). (b) Orography (in meters), coastal domain, buoy locations (red triangles; $\mathrm{CB}$ and $\mathrm{DB}$ ), points where the numerical results are examined in detail (red dots: $\mathrm{P} 1, \mathrm{P} 2$ and $\mathrm{P} 3$ ) and high-frequency (HF) radar coverage area (in orange).

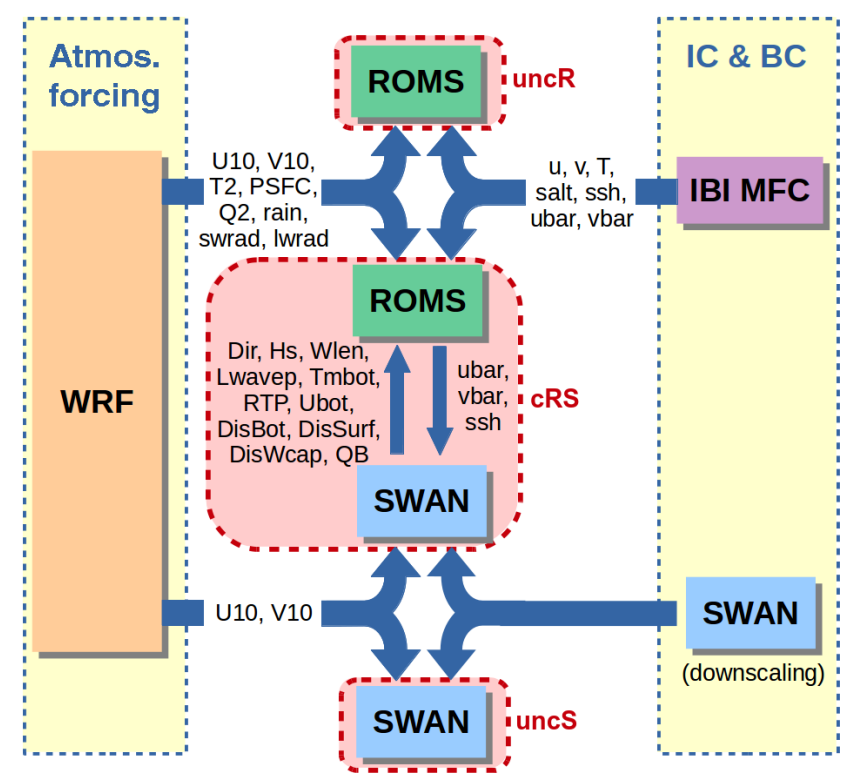

Figure 2. Configuration of setup run. In red is the name given to each configuration.

energy spectra from the coarser domain to the boundary of the smaller domain. The WRF model provided by the SMC provides the $10 \mathrm{~m}$ surface winds $(U 10, V 10)$ forcing and the initial conditions have been obtained running the model in stationary mode.

In the SWAN model, non-stationary conditions, spherical coordinates and nautical convention have been selected. The wave growth by wind is computed with a sum of a linear term and an exponential term. For the linear growth, the expression from Cavaleri and Malanotte-Rizzoli (1981) is used, and for the exponential growth, the expression and coefficients from Komen et al. (1984) are used. The nonlinear quadruplet wave interactions are integrated by a fully explicit computation of the nonlinear transfer with the discrete interaction approximation (DIA; proposed by Hasselmann et al., 1985) per sweep (using default coefficients). For the whitecapping, the Komen et al. (1984) formulation is used with $C_{d s}=2.36 \times 10^{-5}, \delta=1$ and $p=4$. Finally, the Joint North Sea Wave Project (JONSWAP) (Hasselmann et al., 1973) bottom friction formulation is added with the default coefficients. The spectrum is discretized with a constant relative frequency resolution of $\Delta f=1.1$ (logarithmic distribution) and a constant directional resolution of $\Delta \theta=10^{\circ}$. The discrete frequencies are defined between 0.01 and $1 \mathrm{~Hz}$. Above the high-frequency cutoff, a diagnostic tail $\left(f^{-4}\right)$ is added.

The initial and boundary conditions for the ROMS model are taken from the Iberian Biscay Irish - Monitoring and Forecasting Centre (IBI-MFC) product. This product (http: //marine.copernicus.eu/, last access: 7 April 2018) includes all main forcings (i.e., tidal forcing, high-frequency atmospheric forcing, freshwater river discharge) and is based on a (eddy-resolving) Nucleus for European Modelling of the Ocean (NEMO) model application run at $1 / 36^{\circ}$ horizontal resolution. The outputs provided by the IBI-MFC used in our numerical model are 3-D daily means of temperature $(T)$, salinity (salt) zonal velocity $(u)$, meridional velocity $(v)$ and 2-D (surface) hourly means of sea surface height (ssh) and barotropic currents ( $u$ bar, $v$ bar). The barotropic currents and the sea surface height are consistently accommodated to the open boundaries with Flather and Chapman conditions. The WRF model provided by the SMC provides the atmospheric forcing fields for the ROMS model, which include $10 \mathrm{~m}$ surface winds $(U 10, V 10)$, atmospheric pressure (PSFC), rela- 
tive humidity $(Q 2)$, atmospheric surface temperature $(T 2)$, precipitation (rain) and shortwave (swrad) and longwave (lwrad) net heat fluxes to the ocean model. The model uses these parameters in the Coupled Ocean-Atmosphere Response Experiment (COARE) algorithm (Fairall et al., 1996) to compute ocean surface stresses and ocean surface net heat fluxes.

The ROMS model implementation includes a generic length-scale turbulent vertical mixing scheme with the $k-\epsilon$ parameterization, a logarithmic profile for the bottom boundary layer with a bottom roughness of $0.005 \mathrm{~m}$ and horizontal mixing terms in geopotential surfaces. The Ebro River discharge is characterized with data from the Automatic Hydrologic Information System of the Ebro River basin (owned by the Confederación Hidrográfica del Ebro, http://www. chebro.es, last access: 18 January 2018). The data used to force the numerical model consist of daily measurements of river runoff and temperature.

In the two-way coupled run, the WCIs are implemented exchanging instantaneous values of coupling fields every $20 \mathrm{~min}$. The wave model provides wave direction (Dir), significant wave height $(H s)$, wave length $($ Wlen), peak wave length (Lwavep), surface and bottom periods ( $R T P$, $T m b o t)$, bottom orbital velocity (Ubot), wave energy dissipation (DisBot, DisSurf, DisWcap) and percent wave breaking $(Q B)$ to the ocean model. These parameters are used by the ocean model in four different mechanisms:

- The first mechanism consists of computing enhanced bottom stresses due to the effect of turbulence in the wave boundary layer by means of the SSW (SherwoodSignell-Warner) implementation of Madsen (1994) bottom boundary layer formulation.

- The seconds mechanism involves computing enhanced surface stresses (SStr) due to changes in the surface roughness $z_{0}$. In contrast to the COARE algorithm used in the uncoupled ROMS run, now the Taylor and Yelland (2001) sea surface roughness closure model, which is sea-state dependent, is used. Now, the $z_{0}$ is derived from $\frac{z_{0}}{H s}=1200(H s / L p)^{4.5}$, where $\mathrm{Lp}$ is the peak wave length.

- The third mechanism is to inject turbulent kinetic energy (TKE) at the surface due to breaking waves. It is introduced as a surface flux of turbulence kinetic energy in the generic length scale method (Warner et al., 2005).

- The fourth mechanism is to include the wave forces using the VF formalism (Uchiyama et al., 2010; Kumar et al., 2012, see Sect. 2.4).

The wave model receives currents $\left(u_{\mathrm{s}}, v_{\mathrm{s}}\right)$ and sea surface height $(s s h)$ from the ocean model. The surface currents $\left(u_{\mathrm{s}}, v_{\mathrm{s}}\right)$ were computed taking into account the vertical distribution of the current profile using the formulation presented by Kirby and Chen (1989), which integrates the near-surface velocity over a depth controlled by the wave number. The presence of an ambient current may change the amplitude (e.g., due to an energy transfer between waves and currents), the frequency (due to the Doppler shift) and the direction (due to current-induced refraction) of the waves. In this sense, the ocean currents modify the wind speed forcing with $S=f\left(U_{\text {wind }}-u_{\mathrm{s}} ; V_{\text {wind }}-v_{\mathrm{s}}\right)$, the wave celerity using the modified group velocities $c_{x}=c_{g x}+u_{\mathrm{s}}, c_{y}=c_{g y}+v_{\mathrm{s}}$ and the wave number (derived from the Doppler shift effect; see Holthuijsen, 2008, Appendix D).

\subsection{Momentum balance description}

The cross-shelf momentum balance is used to analyze the coupling effects on the circulation over the continental shelf. The simplified equations for the VF approach can be obtained after removing the curvilinear terms, body forces and horizontal and vertical mixing, and then using Cartesian coordinates (Kumar, 2013):

$$
\begin{aligned}
\frac{\partial \bar{v}}{\partial t}+ & \frac{1}{H}\left[\frac{\partial}{\partial x}\left(\int u v \mathrm{~d} z\right)+\bar{v}\left(\frac{\partial}{\partial x} \int u^{\mathrm{st}} \mathrm{d} z\right)\right. \\
& \left.+\bar{v}\left(\frac{\partial}{\partial y} \int v^{\mathrm{st}} \mathrm{d} z\right)\right]+ \\
\overline{u^{\mathrm{st}}} & {\left[\frac{\partial}{\partial x}\left(\int v \mathrm{~d} z\right)-\frac{\partial}{\partial y}\left(\int u \mathrm{~d} z\right)\right]+f \bar{u}+f \overline{u^{\mathrm{st}}} } \\
& =-\frac{1}{\rho_{0}} \frac{\partial p}{\partial y}+\overline{F^{\mathrm{w} y}}+\frac{\tau_{\mathrm{s}}^{y}}{\rho_{0} H}-\frac{\tau_{\mathrm{b}}^{y}}{\rho_{0} H},
\end{aligned}
$$

where $u$ and $v$ are the along-shore and cross-shore velocity components, $u^{\mathrm{st}}$ and $v^{\mathrm{st}}$ are the Stokes velocities, the overbar indicates depth averaging, $H$ is the total water depth, $f$ is the Coriolis parameter, $\rho_{0}$ is the reference density, $\tau_{\mathrm{s}}^{y}$ and $\tau_{\mathrm{b}}^{y}$ are the surface and bottom stress, respectively, and $F^{\mathrm{w} y}$ is the non-conservative wave forcing. Going from left to right, the terms in the equations are local acceleration $(A C C)$, horizontal advection $(H A)$, horizontal vortex force $(H V F)$, Coriolis $(C O R)$, Stokes-Coriolis $(S t C O R)$, pressure gradient $(P G)$, non-conservative wave forces $(W F)$, surface stress $S S t r)$ and bottom stress $(B S t r)$. The wave-induced terms include part of the $H A$ term, the $H V F$ term, the StCOR term and the $W F$ term.

The pressure gradient term includes (Kumar et al., 2012) the Eulerian non-WEC contribution $\left(P^{\mathrm{c}}\right)$ and the WEC contribution $\left(P^{\mathrm{WEC}}\right)$, which can be decomposed in a quasi-static response $\left(P^{\mathrm{qs}}\right)$, a Bernoulli head $\left(P^{\mathrm{bh}}\right)$ and a surface pressure boundary correction $\left(P^{\mathrm{pc}}\right)$ :

$\nabla p=P^{\mathrm{c}}+P^{\mathrm{WEC}}=P^{\mathrm{c}}+P^{\mathrm{qs}}+P^{\mathrm{bh}}+P^{\mathrm{pc}}$.

The non-conservative wave forcing term $F^{\mathrm{w} y}$ includes accelerations due to (Kumar et al., 2012) bottom streaming 
$\left(B^{\mathrm{bf}}\right)$, surface streaming $\left(B^{\mathrm{sf}}\right)$ and wave breaking $\left(B^{\mathrm{wb}}\right)$. The latter is further decomposed in whitecapping-induced acceleration $\left(B^{\text {wcap }}\right)$, bathymetry-induced breaking and acceleration $\left(B^{\mathrm{b}}\right)$ and wave rollers and rollers acceleration $\left(B^{\mathrm{r}}\right)$ :

$F^{\mathrm{w} y}=B^{\mathrm{bf}}+B^{\mathrm{sf}}+B^{\mathrm{wb}}=B^{\mathrm{bf}}+B^{\mathrm{sf}}+B^{\mathrm{wcap}}+B^{\mathrm{b}}+B^{\mathrm{r}}$.

\subsection{Skill assessment techniques}

In order to assess the model behavior, the estimation of bias, the root mean square deviation (RMSD), the Pearson correlation (Pearson's $r$ ) and the model skill score ( $d$, following the method presented in Willmott, 1981) are undertaken. These values are defined as follows:

bias $=\frac{1}{N} \sum\left(X_{\text {model }}-X_{\text {obs }}\right)$

$\mathrm{RMSD}=\sqrt{\frac{1}{N} \sum\left(X_{\text {model }}-X_{\mathrm{obs}}\right)^{2}}$

$r=\frac{\sum\left(\left(X_{\text {model }}-\overline{X_{\text {model }}}\right)\left(X_{\text {obs }}-\overline{X_{\text {obs }}}\right)\right)}{\sqrt{\sum\left(X_{\text {model }}-\overline{X_{\text {model }}}\right)^{2}} \sqrt{\sum\left(X_{\text {obs }}-\overline{X_{\text {obs }}}\right)^{2}}}$

$d=1-\frac{\sum\left|X_{\text {model }}-X_{\mathrm{obs}}\right|^{2}}{\sum\left(\left|X_{\text {model }}-\overline{X_{\mathrm{obs}}}\right|+\left|X_{\mathrm{obs}}-\overline{X_{\mathrm{obs}}}\right|\right)^{2}}$,

where $N$ is the number of samples. Pearson's $r$ describes consistent proportional increases or decreases about respective means of the two quantities, but it makes too few distinctions among the type or magnitudes of possible covariations (Willmott, 1981). By contrast, $d$ is not a measure of correlation or association in the formal sense but rather a measure of the degree to which a model's predictions are error-free. Unlike $r, d$ is sensitive to differences between the observed and predicted means as well as to certain changes in proportionality (Willmott, 1981). Note that analogously to $r, d$ is measured from 0 to 1,1 denoting maximum agreement. When computing these metrics, the first $24 \mathrm{~h}$ of the model results were rejected, in order to exclude the possible spinup of the model. The time series analyses have demonstrated that $24 \mathrm{~h}$ are enough to spin up the model. Besides, it has to be noticed that the ROMS model is not initialized from zero velocities; it reads the initial conditions from the IBI-MFC model.

For circular data, e.g., wave direction, the metrics are computed as follows:

$$
\begin{aligned}
& \text { bias }=\tan ^{-1}\left(\frac{\frac{1}{N} \sum \sin \left(X_{\text {model }}-X_{\text {obs }}\right)}{\frac{1}{N} \sum \cos \left(X_{\text {model }}-X_{\mathrm{obs}}\right)}\right) \\
& \operatorname{RMSD}=\sqrt{-2 \cdot \ln \left(\frac{1}{N} \sum \cos \left(X_{\mathrm{obs}}-X_{\text {model }}\right)\right)} \\
& r=\frac{\sum\left(\sin \left(X_{\text {model }}-\overline{X_{\text {model }}}\right) \sin \left(X_{\mathrm{obs}}-\overline{X_{\mathrm{obs}}}\right)\right)}{\left.\sqrt{\sum \sin ^{2}\left(X_{\text {model }}-\overline{X_{\text {model }}}\right) \sum \sin ^{2}\left(X_{\mathrm{obs}}-\overline{X_{\mathrm{obs}}}\right.}\right)} .
\end{aligned}
$$

\section{Results}

\subsection{Numerical model skill assessment}

The ROMS and SWAN models for the same study period and the same model configurations have been validated thoroughly in previous studies (Ràfols et al., 2017a, b). The aim of this section is to analyze the skill of the coupled run in comparison to the uncoupled runs.

The first step in the numerical skill assessment is to examine the quality of the wind field, which is used to force the numerical models. Table 1 shows the bias, RMSD, $r$ and $d$ obtained from the comparison between the DB-measured data and the wind field provided by the SMC (which has been extrapolated from 10 to $3 \mathrm{~m}$ ). Figure 3 presents the time series for the modeled and measured wind intensity at DB. The comparison shows a slight underestimation of the wind intensity but the main underestimation does not correspond to the NW wind events, which are the focus of this study. During the study period, four NW wind-jet events have been selected (see the red boxes in Fig. 3). These events were previously analyzed in Ràfols et al. (2017b), where statistical metrics for each episode were provided. To see the temporal evolution of a wind jet more clearly, in Fig. 4a the time series during the wind-jet E3 event are presented, which is the event that spans more in space and thus can be observed in the DB location. Overall, the modeled wind shows less underestimation (in comparison to measured values) during the wind-jet events, and the wind-jet temporal evolutions are properly reproduced.

Table 1 also shows the statistics obtained from the comparison of the measured wave parameters at DB and the modeled ones. The $H s$ and $\mathrm{Tm}_{02}$ time series at DB during the wind-jet E3 event are shown in Fig. 4b and c, respectively. The mean wave period $\left(\mathrm{Tm}_{02}\right)$ is defined as follows:

$\operatorname{Tm}_{02}=2 \pi\left(\frac{\iint \omega^{2} E(\omega, \theta) \mathrm{d} \omega \mathrm{d} \theta}{\iint E(\omega, \theta) \mathrm{d} \omega \mathrm{d} \theta}\right)^{-1 / 2}$,

where $E(\omega, \theta)$ is the variance density and $\omega$ is the absolute radian frequency. The latter is determined by the Doppler shift phenomenon with $\omega=\sigma+\mathbf{k} \cdot \mathbf{U}$, where $\sigma$ is the relative 


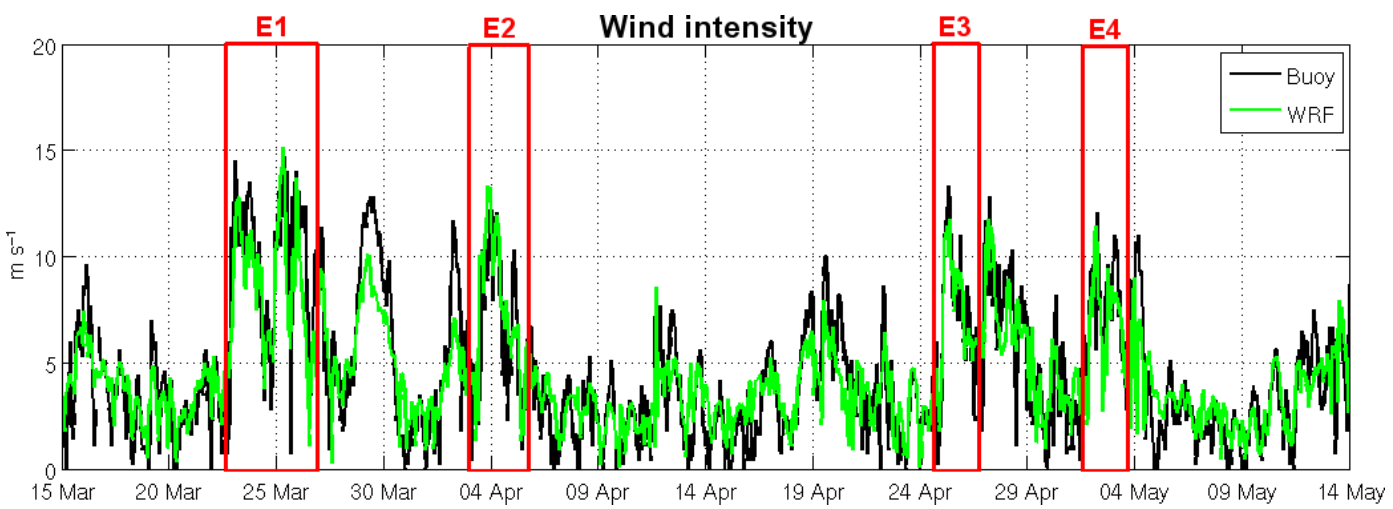

Figure 3. Comparison between the wind measured by the DB buoy (black) and the one modeled by the WRF model and used as input for the SWAN and ROMS models (green); see statistics in Table 1. The red boxes are the four wind-jet events.

Table 1. Statistics comparing the $3 \mathrm{~m}$ wind and the modeled wave parameters with the DB data.

\begin{tabular}{llllrr}
\hline & & Bias & RMSD & $r$ & $d$ \\
\hline \multirow{2}{*}{ Wind } & & $-0.04 \mathrm{~m} \mathrm{~s}^{-1}$ & $1.83 \mathrm{~m} \mathrm{~s}^{-1}$ & 0.83 & 0.89 \\
\hline \multirow{2}{*}{$H s$} & uncS & $-0.25 \mathrm{~m}$ & $0.38 \mathrm{~m}$ & 0.89 & 0.86 \\
& $c R S$ & $-0.28 \mathrm{~m}$ & $0.40 \mathrm{~m}$ & 0.90 & 0.85 \\
\hline \multirow{2}{*}{$\operatorname{Tm}_{02}$} & uncS & $-0.95 \mathrm{~s}$ & $1.09 \mathrm{~s}$ & 0.79 & 0.67 \\
& $c R S$ & $-0.34 \mathrm{~s}$ & $0.52 \mathrm{~s}$ & 0.85 & 0.86 \\
\hline \multirow{2}{*}{ Dir } & uncS & $-9.39^{\circ}$ & $34.89^{\circ}$ & 0.84 & - \\
& $c R S$ & $-10.34^{\circ}$ & $36.37^{\circ}$ & 0.84 & - \\
\hline
\end{tabular}

radian frequency (i.e., as observed in a frame of reference moving with the current velocity), $\mathbf{k}$ the wave number vector and $\mathbf{U}$ the current vector. In absence of currents, the relative radian frequency is equal to the absolute radian frequency. Regarding the Table 1 results, in general, the $H s$ does not show relevant differences between the uncS run and the $c R S$ run results. It is important to note the negative bias, which indicates that the $H s$ parameter is slightly underestimated. This is a clear consequence of the previously mentioned underestimation of the wind. In contrast, $\mathrm{Tm}_{02}$ shows a clear improvement when the models are coupled. In this case, keeping in mind the $\mathrm{Tm}_{02}$ definition, it is important to note that the buoy measures at a fixed location (i.e., in an absolute frame) and, for this reason, the comparison of the measured period with the modeled one is more realistic when the results from the $c R S$ run are used (i.e., the absolute period) instead of the results from the $u n c R$ run (i.e., the relative period). Therefore, the differences found in the $\mathrm{Tm}_{02}$ parameter might be explained, in part but not uniquely, by the differences in frequency due to the Doppler shift phenomena that are included in the wave model when the models are coupled.

Table 2, where the modeled data are compared with measurements from $\mathrm{CB}$, shows similar results to Table 1 . The
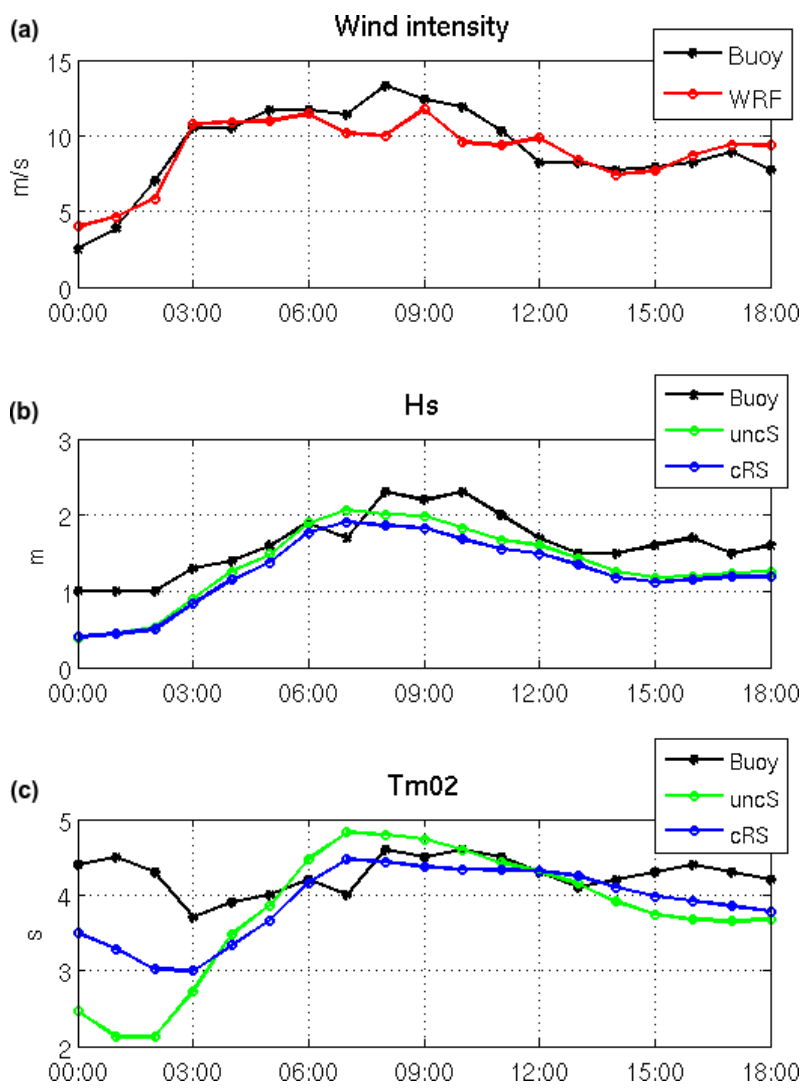

Figure 4. (a) Wind intensity, (b) $H s$ and (c) $\mathrm{Tm}_{02}$ time series at DB during the wind-jet E3 event (25 April 2014). In black: the measured data; in red: the WRF model data; in green: the uncS run results; in blue: the $c R S$ run results.

most noticeable difference between the two tables is the Dir parameter, which shows better agreement in the DB case. The comparison at DB shows very good results with strong correlations and no relevant differences between the uncS and $c R S$ runs. In contrast, at the CB location, the agreement with observations is smaller but a clear improvement of the 
Table 2. Statistics comparing the modeled wave parameters with the $\mathrm{CB}$ data.

\begin{tabular}{llllrr}
\hline & & Bias & RMSD & $r$ & $d$ \\
\hline \multirow{2}{*}{$H s$} & uncS & $-0.14 \mathrm{~m}$ & $0.23 \mathrm{~m}$ & 0.87 & 0.79 \\
& $c R S$ & $-0.17 \mathrm{~m}$ & $0.24 \mathrm{~m}$ & 0.89 & 0.79 \\
\hline \multirow{2}{*}{$\operatorname{Tm}_{02}$} & uncS & $-1.24 \mathrm{~s}$ & $1.43 \mathrm{~s}$ & 0.42 & 0.48 \\
& $c R S$ & $-0.34 \mathrm{~s}$ & $0.64 \mathrm{~s}$ & 0.71 & 0.79 \\
\hline \multirow{2}{*}{ Dir } & uncS & $4.11^{\circ}$ & $33.06^{\circ}$ & 0.46 & - \\
& $c R S$ & $-0.99^{\circ}$ & $25.97^{\circ}$ & 0.52 & - \\
\hline
\end{tabular}

Table 3. Statistics comparing the modeled water currents at P3 with data from the HF radar.

\begin{tabular}{|c|c|c|c|c|c|}
\hline & & Bias & RMSD & $r$ & $d$ \\
\hline \multirow[b]{2}{*}{$u$} & uncS & $-4.20 \mathrm{~cm} \mathrm{~s}^{-1}$ & $14.02 \mathrm{~cm} \mathrm{~s}^{-1}$ & 0.56 & 0.73 \\
\hline & $c R S$ & $-1.49 \mathrm{~cm} \mathrm{~s}^{-1}$ & $13.71 \mathrm{~cm} \mathrm{~s}^{-1}$ & 0.55 & 0.74 \\
\hline \multirow{2}{*}{$v$} & uncS & $3.50 \mathrm{~cm} \mathrm{~s}^{-1}$ & $14.18 \mathrm{~cm} \mathrm{~s}^{-1}$ & 0.65 & 0.77 \\
\hline & $c R S$ & $2.88 \mathrm{~cm} \mathrm{~s}^{-1}$ & $14.86 \mathrm{~cm} \mathrm{~s}^{-1}$ & 0.66 & 0.77 \\
\hline
\end{tabular}

results is obtained when the currents are considered (i.e., with the $c R S$ run).

In Table 3, the modeled water currents are compared with the HF radar surface current measurements. The metrics presented in the table correspond to point P3 and show good agreement, with skill metrics that are in accordance with values found in previous work when comparing HF radar data with modeled data (Port et al., 2011; O'Donncha et al., 2015; Lorente et al., 2016). Comparing the results from the uncR run with the results from the $c R S$ run, some differences are observed (e.g., a decrease of the bias is obtained in the crossshelf velocity component when the models are coupled), but the differences are not relevant enough to discern if one configuration agrees better than the other. A similar conclusion can be reached analyzing the scatter plots (not shown) comparing the HF radar data with the modeled data at P3. The differences between the $c R S$ and $u n c R$ runs are not relevant, but the modeled cross-shelf components show a better fit with the measurements, with regression slopes of 1.01 for both runs, than the along-shelf components, with regression slopes of 0.64 and 0.68 , respectively. In general, the modeled water currents show larger intensities than the measured ones.

\subsection{Description of the coupling effects on currents}

Figure 5 compares $u n c R$ and $c R S$ run results during the windjet E3 event at P1 (73.7 $\mathrm{m}$ depth) and P3 (98.9 $\mathrm{m}$ depth) along with $\mathrm{HF}$ radar subinertial water surface current at P3. Following Ràfols et al. (2017a), the subinertial currents have been calculated using a 10th-order Butterworth filter with a cutoff period of $30 \mathrm{~h}$. The figure also shows the wind intensity evolution at each point and the $H s$ comparison between the uncS and $c R S$ run results. The wind-jet E3 event starts on 25 April at 02:00 UTC, forms very quickly, reaches its maximum intensity at 06:00 UTC and fades gradually. The water current time series show that, during the wind-jet peak, the cross-shelf current magnitude increases (it becomes more negative; i.e., it flows offshore) and, throughout the windjet event, the along-shelf component becomes more negative (i.e., southwestward). Comparing the results from the $u n c R$ and $c R S$ runs, it is observed that larger differences occur at the shallowest point (P1), with differences up to $20 \mathrm{~cm} \mathrm{~s}^{-1}$, while at $\mathrm{P} 3$ both runs present very similar results (with differences lower than $10 \mathrm{~cm} \mathrm{~s}^{-1}$ ). No measured data are available for P1; thus, it cannot be discerned which run best fits the observation. In contrast, at P3, the modeled results can be compared with the HF radar data, but it is difficult to state which simulation best reproduces the observations. The influence of waves at the cross-shelf circulation is limited and the surface circulation of both runs presents similar patterns.

With the aim of visualizing the differences in the current patterns and the spatial variability between the different runs, in Fig. 6, the measured HF radar currents are compared with the surface currents obtained with the $u n c R$ and $c R S$ runs in four snapshots, which correspond to the evolution of the wind-jet E3 event. For clarity, the figure presents the results up to the mid-slope. The modeled water currents are more intense than the water currents measured by the HF radar but the circulation patterns are consistent. There are slight differences between the uncR run results and the $c R S$ run results. An increase of the current intensity is observed at the start of the wind jet when the waves are considered in the ROMS model (Fig. 6c and d, second column). In addition, the region affected by the wind jet seems to be expanded to the northeast, resulting in stronger water currents in the $c R S$ run. Nevertheless, the main current patterns obtained with both runs are very similar and coincide with the behavior presented in Ràfols et al. (2017a).

Figure 7 shows the $H s$ and surface water current mean of the hourly instantaneous differences considering the whole study period, the whole study period except the wind-jet events and just the four wind-jet events. It is observed that the major differences are obtained during the wind-jet events. The mean differences obtained for the whole period are very similar to the mean differences under no wind-jet conditions, with differences shorter than $\pm 5 \mathrm{~cm} \mathrm{~s}^{-1}$. During windjet conditions, a clear decrease of the surface water current intensity is observed at the wind-jet axis when the waves are considered, but the differences are less than $10 \mathrm{~cm} \mathrm{~s}^{-1}$. In contrast, at shallow regions, the surface water current intensities are increased, showing differences up to $15-20 \mathrm{~cm} \mathrm{~s}^{-1}$. An increase of the current intensity is also observed at the northeast corner of the domain but there the differences are just around $5 \mathrm{~cm} \mathrm{~s}^{-1}$. 

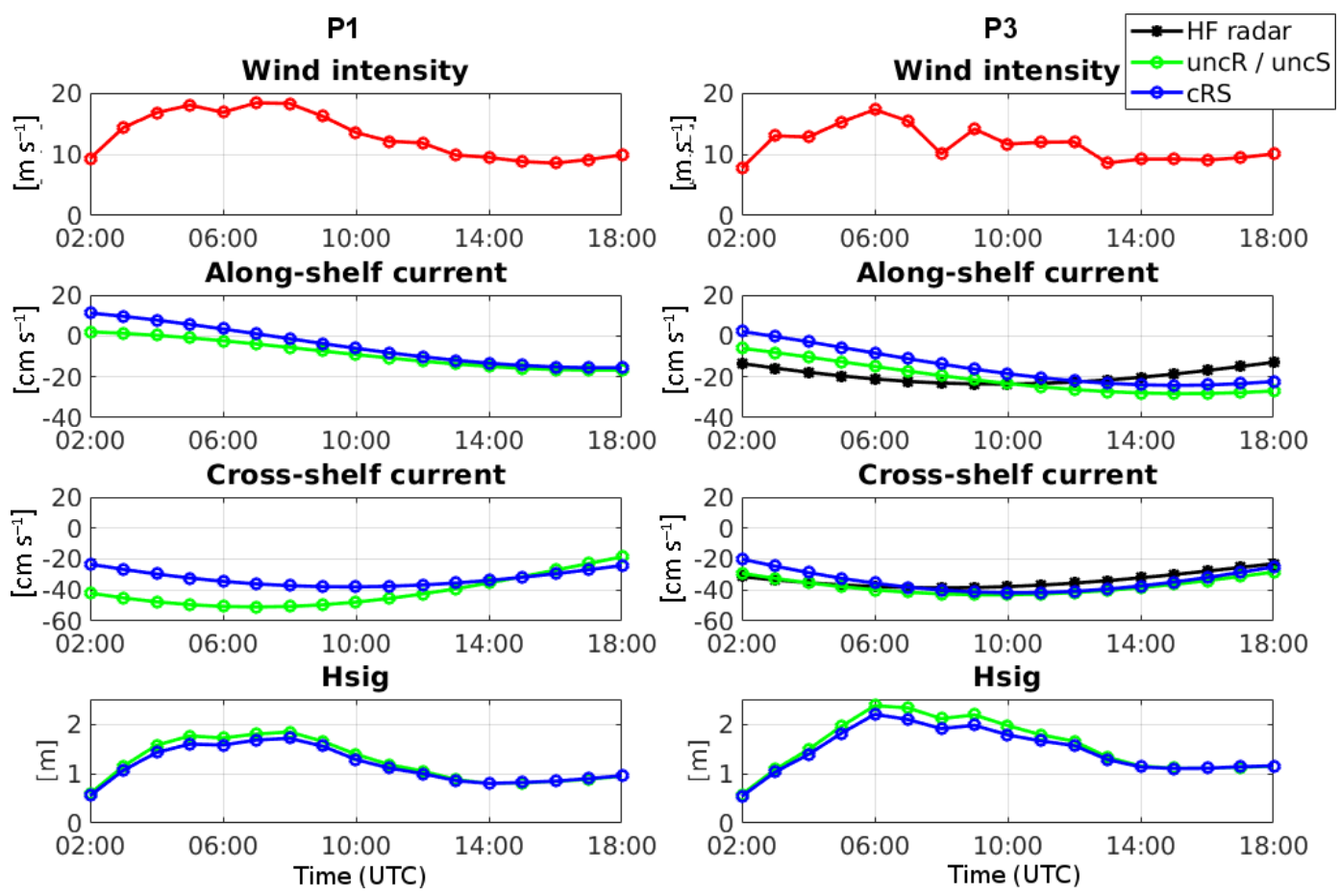

Figure 5. Wind intensity, along- and cross-shelf subinertial surface currents and $H s$ time series at P1 and P3 during the wind-jet E3 event (25 April 2014). Negative values indicate offshore and southwestward directions. In red: the modeled wind intensity; in black: the HF radar data; in green: the $u n c R$ and $u n c S$ runs' results; in blue: the $c R S$ run results.

The evolution of the buoyancy or Brunt-Väisälä frequency $\left(N=\sqrt{-\frac{g}{\rho_{0}} \frac{\partial \rho(z)}{\partial z}}\right.$, where $\rho_{0}$ is the reference density and $g$ is the gravitational acceleration) is investigated in order to analyze the differences between the uncR and the $c R S$ run results in the water column structure. Figure 8 shows the BruntVäisälä frequency evolution (before and after the wind jet) at P3 during the four wind-jet events for both $u n c R$ and $c R S$ runs. It is observed that the vertical structure of the water column is significantly different when the waves are taken into account. The $c R S$ run always presents a less stratified water column, both before and after the wind jet. When a wind jet occurs, the expected behavior is that the water column will become less stratified after the wind jet than before it. This is observed in all the studied wind-jet events but the surface mixed-layer depth (SML; i.e., the distance from the surface to the top of the pycnocline) after the wind jet obtained with the $c R S$ run is larger (i.e., deeper) than the one obtained by the $u n c R$ run. Thus, the vertical mixing is significantly enhanced when the waves are taken into account.

Analyzing the results from $u n c R$ and $c R S$ runs, it is found that there is a clear enhancement of the TKE when the waves are considered, also with some increase of the SStr (see Fig. 9). Note that the SStr felt by the ocean is equal to the air-side stress, which in the $c R S$ run includes the wave-dependent sea surface roughness, but it does not account for the stress acting on waves and the dissipation due to wave breaking. The mean TKE and SStr values obtained with the model during the wind-jet E3 event at $\mathrm{P} 3$ shift from $8.14 \times 10^{-4} \mathrm{~m}^{2} \mathrm{~s}^{-2}$ and $0.25 \mathrm{~N} \mathrm{~m}^{-2}$ with the uncR run to $5.13 \times 10^{-3} \mathrm{~m}^{2} \mathrm{~s}^{-2}$ and $0.31 \mathrm{~N} \mathrm{~m}^{-2}$ with the $c R S$ run. Additionally, the TKE and SStr peak coincide with the wind-jet peak (25 April at 06:00 UTC) and the peak values found at P3 are $2.44 \times 10^{-3} \mathrm{~m}^{2} \mathrm{~s}^{-2}$ and $0.75 \mathrm{~N} \mathrm{~m}^{-2}$ for the uncR run, and $1.11 \times 10^{-2} \mathrm{~m}^{2} \mathrm{~s}^{-2}$ and $0.88 \mathrm{~N} \mathrm{~m}^{-2}$ for the $c R S$ run. Thus, the TKE is 1 order of magnitude stronger when the waves are considered, which leads to an enhancement of the water column mixing and thus a decrease of the stratification.

In order to evaluate how the waves' effects are taken into account in the momentum balance, the terms of Eq. (1) are analyzed. During a calm period before the wind jet, the cross-shelf momentum balance is between the $P G$ and $C O R$ terms, and the remaining terms are (at least) 1 order of magnitude smaller. Thus, the coupling effects on the momentum balance are negligible. In contrast, during a windjet event, more terms are involved in the cross-shelf momentum balance. From the coastline to $4 \mathrm{~km}$ offshore ( $50 \mathrm{~m}$ depth), the $W F$ term $\left(1.85 \times 10^{-5} \mathrm{~m} \mathrm{~s}^{-2}\right)$ is on the same order of magnitude as the $P G\left(2.42 \times 10^{-5} \mathrm{~m} \mathrm{~s}^{-2}\right)$, $S \operatorname{Str}\left(2.73 \times 10^{-5} \mathrm{~m} \mathrm{~s}^{-2}\right)$ and $H A\left(1.99 \times 10^{-5} \mathrm{~m} \mathrm{~s}^{-2}\right)$ terms. From that point to tens of kilometers offshore, the $P G$ $\left(1.34 \times 10^{-5} \mathrm{~m} \mathrm{~s}^{-2}\right)$ term is mainly balanced by the SStr $\left(1.07 \times 10^{-5} \mathrm{~m} \mathrm{~s}^{-2}\right)$ and $W F\left(5.05 \times 10^{-6} \mathrm{~m} \mathrm{~s}^{-2}\right)$ terms, also including some contribution from the $C O R$ and $H A$ terms. However, the $W F$ term weight is half the weight of the SStr 

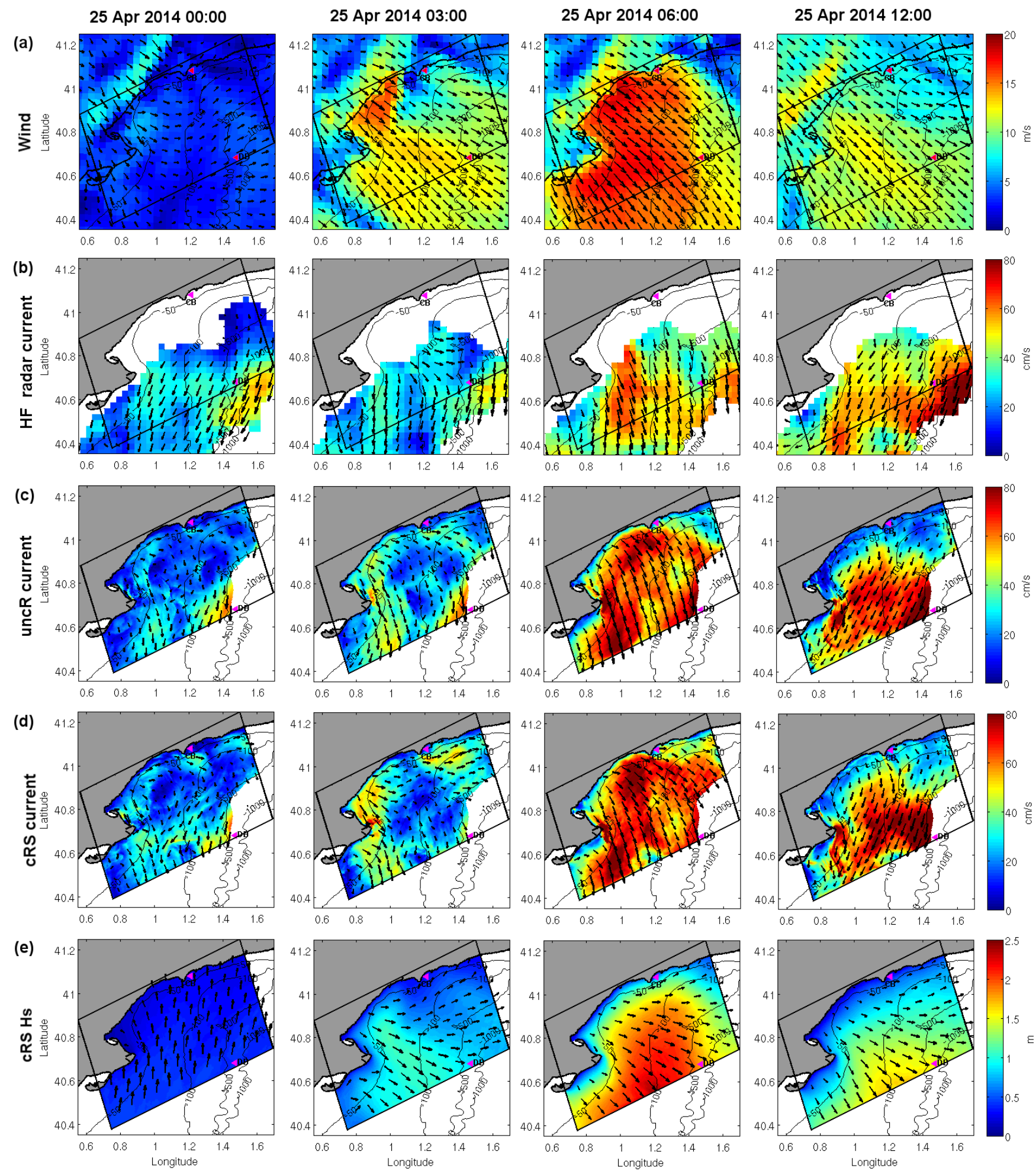

Figure 6. Results for the wind-jet E3 event. (a) $10 \mathrm{~m}$ wind intensity; (b) HFR current intensity; (c) uncR-modeled surface current intensity; (d) $c R S$-modeled surface current intensity; (e) $c R S$-modeled $H s$ and mean wave direction. For clarity, the results are shown up to the midslope. The CB and DB locations are shown with pink triangles. 

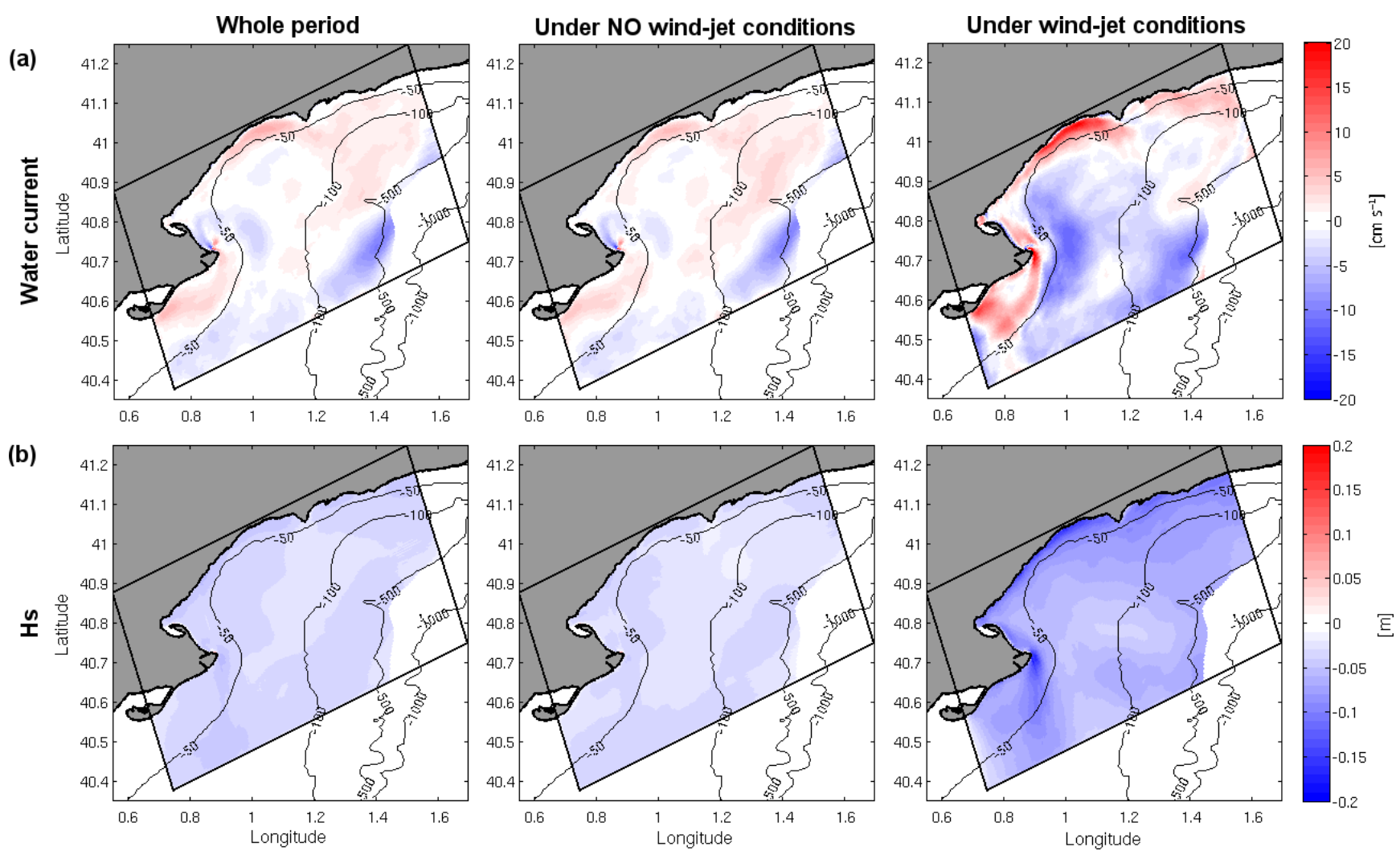

Figure 7. (a) Surface water current and (b) $H s$ mean of the hourly instantaneous differences between the $u n c S / u n c R$ runs and the $c R S$ run considering the whole period (left), the whole period except the wind-jet events (center) and during the four wind-jet events (right). Positive values correspond to $c R S$ value $>$ uncS/uncR value.
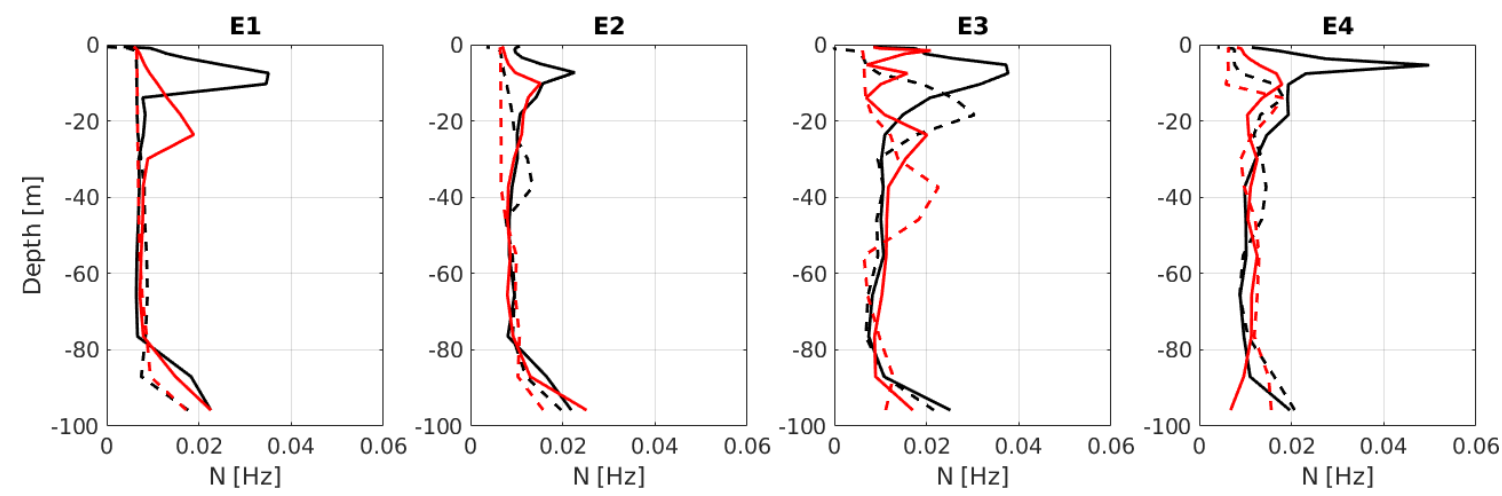

Figure 8. Comparison of the Brunt-Väisälä frequency at the start (solid line) and the end (dashed line) of each wind-jet event obtained from the results of the $u n c R$ (in black) and $c R S$ runs (in red) at P3.

term. Thus, the $W F$ term included by the VF formalism plays an important role in the momentum balance in the first kilometers offshore (i.e., in coastal regions). Analyzing the $W F$ term, it is found that its main contributor is the surface streaming ( $B^{\text {sf }} ; 1.65 \times 10^{-5}$ and $3.94 \times 10^{-6} \mathrm{~m} \mathrm{~s}^{-2}$ for shallow and deep water, respectively), especially in shallow waters, with also some contribution of the wave-breaking term $\left(B^{\mathrm{b}} ; 2.01 \times 10^{-6}\right.$ and $1.11 \times 10^{-6} \mathrm{~m} \mathrm{~s}^{-2}$, respectively). Regarding the $P G$ term, its weight is mainly due to the non-
WEC contributions $\left(P^{\mathrm{c}} ; 1.60 \times 10^{-5}\right.$ and $1.37 \times 10^{-5} \mathrm{~m} \mathrm{~s}^{-2}$, respectively) together with some contribution of the quasistatic response $\left(P^{\mathrm{qs}} ; 1.37 \times 10^{-5}\right.$ and $\left.3.21 \times 10^{-6} \mathrm{~m} \mathrm{~s}^{-2}\right)$.

\subsection{Description of the coupling effects on waves}

The irregular nature of wind causes irregular wind waves of different heights, periods and directions. For this reason, wind waves are usually described using spectral techniques, 

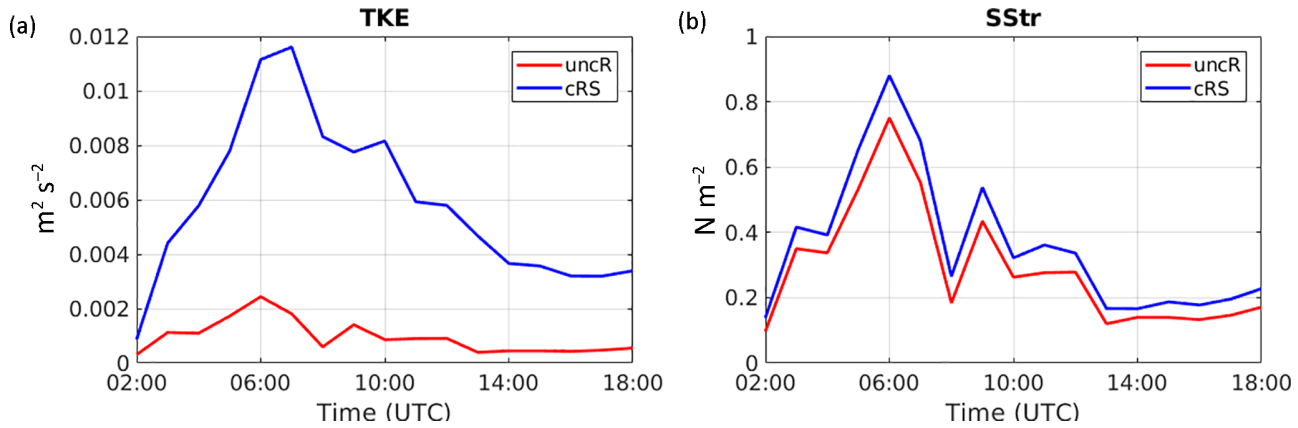

Figure 9. Time series comparison of the TKE (a) and SStr (b) obtained from the results of the uncR (in red) and $c R S$ run (in blue) at P3 during the wind-jet E3 event (25 April 2014).

where the random motion of the sea surface is treated as a summation of harmonic wave components. In Fig. 10, the wave response during a wind-jet event is analyzed in terms of the variance density spectrum $E(f, \theta)$ evolution obtained from the numerical model. The one- and two-dimensional frequency-direction spectra evolution at $\mathrm{P} 2$ (i.e., at the windjet axis) obtained with the $u n c S$ and $c R S$ runs during the wind-jet E3 event are compared. The runs show similar spectra evolution patterns. When the wind jet starts, the wave field is adapted to the new wind, generating a bimodal spectrum with a wider peak at the NW (which is consistent with the new wind direction; i.e., it is a new sea system) and a peak at the south corresponding to the "old" sea system. At the peak of the wind jet, the spectra are dominated by the new sea system and, when the wind-jet intensity diminishes, another new sea system occurs, while the energy due to the wind jet decreases gradually. In addition, a swell system appears at the northeast, due to the coexistence of NW wind at the region and northerly wind at the northern part of the coast (Ràfols et al., 2017b). The main difference between the uncS and $c R S$ runs is that the spectra obtained with the $c R S$ run present less energy at the peak than those obtained with the $u n c S$ run. An energy increase at higher frequencies (i.e., at the spectrum tail) can also be observed when the currents are considered, but overall the $u n c S$ run presents more energy. A less energetic spectrum means shorter $H s$ values, which is consistent with the values obtained from the numerical results.

In Figs. 5 and 6, it is observed that, during the wind-jet event, the wave field responds directly to the wind. In Fig. 6, the 2-D Hs maps show a clear increase of the wave height at the wind-jet axis that, at the wind-jet peak, reaches values up to $2.43 \mathrm{~m}$. The time series presented in Figs. 4 and 5 show that the $H s$ diminishes when the water currents are considered and that the major differences $(\sim 15-20 \mathrm{~cm})$ occur during the wind-jet peak. Similar results are shown in Fig. 7, where the mean differences show that the $H s$ from the $c R S$ run tend to be shorter than the $H s$ from the uncS run and that the major differences are observed during the wind-jet events. Under such conditions, the mean differences in shallow regions reach values of $15 \mathrm{~cm}$, while the mean difference at the wind-jet axis is around $6 \mathrm{~cm}$. Comparing the results from the $c R S$ and the $u n c S$ runs, it is found that coupling the models produces a mean effect of $11 \%$ in the $\mathrm{Hs}$ parameter at the CB location and a mean effect of $4 \%$ at DB location.

In order to analyze the $H s$ differences obtained with the two runs, Fig. 11 shows the differences in $H s$ at P2, distinguishing the differences in the wave and current propagation directions. It is found that the $H s$ from the $c R S$ run tends to be shorter (stronger) than the $H s$ from the $u n c S$ run when the difference between the propagation direction of waves and currents is shorter (stronger). This is to say that considering the coupling effects results in a decrease (increase) of $H s$ when the waves and the currents propagate in the same (opposite) direction. In general, the $H s$ differences between the runs are small $(\Delta H s<5 \mathrm{~cm})$. However, during the NW wind jets, these differences increase up to $10-14 \mathrm{~cm}$ and, in the case of the $\mathrm{E} 3$ event, reach $20 \mathrm{~cm}$. The mean differences observed at this point correspond to $10 \%$ of $\mathrm{Hs}$.

The $\mathrm{Tm}_{02}$ obtained with the $c R S$ tends to be longer than the one obtained with the uncS excepting the wind-jet event periods, where the $\mathrm{Tm}_{02}$ from the coupled run is shorter (see Fig. 4). This is consistent with the frequency increase in the $c R S$ run detected in the spectra analysis during the wind-jet E3 event. Figure 12 shows the $\mathrm{Tm}_{02}$ and Dir time series obtained with the $u n c S$ and the $c R S$ runs compared to the CB-measured data. Note that the CB location is not affected by the wind jet. Qualitatively, the $c R S$ run shows a clear improvement in the agreement of the $\mathrm{Tm}_{02}$ results with the measurements, which is consistent with the statistical parameters collected in Tables 1 and 2. Comparing the results from the $c R S$ and the uncS runs, it is found that coupling the models produces an average effect of $48 \%$ in the $\mathrm{Tm}_{02}$ parameter at the $\mathrm{CB}$ location. This effect is reduced to $27 \%$ at the $\mathrm{DB}$ location.

Regarding the mean wave direction, no relevant differences are observed between the $u n c S$ and $c R S$ runs in deep water (not shown). However, similarly to the results presented in Table 2, Fig. 12b shows that at the CB location (i.e., in shallow waters) the mean wave direction is improved during the wind-jet events. Analyzing the mean wave direc- 

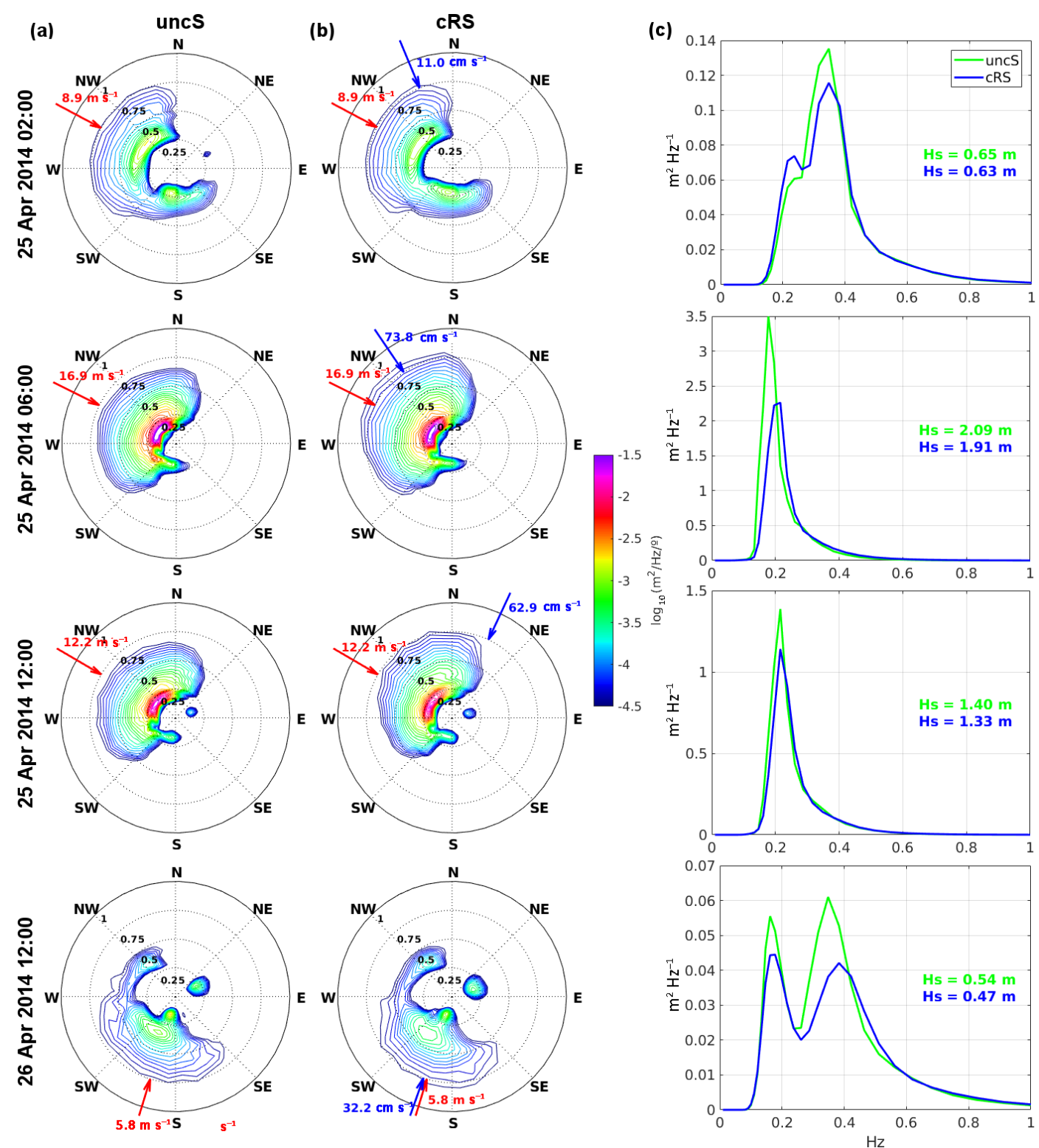

Figure 10. Spectra evolution during the E3 event at P2. (a) 2-D spectrum from uncS run. (b) 2-D spectrum from $c R S$ run. (c) 1-D spectra from both runs and the corresponding $H s$ values. The arrows shown in panels (a) and (b) indicate the direction and magnitude of wind (red) and current (blue).

tion differences between the $u n c S$ and $c R S$ runs, it is found that relevant differences occur near the coastline.

\section{Discussion}

\subsection{Effects of coupling on the current field}

The main differences between the uncR and $c R S$ runs have been detected in the water column structure. The vertical mixing of the water column is stronger when the waves are considered. This behavior can be explained by the TKE injection and the use of a wave-dependent sea surface stress in the $c R S$ run. Similar results have been observed in previous work. Rong et al. (2014) studied the WCI over the Texas-Louisiana shelf and found that the wave effects can redistribute the freshwater both vertically and horizontally and thus affect the stratification. Bruneau and Toumi (2016) also found that the mixed-layer depths were enhanced in presence of waves. Niu and Xia (2017) investigated how the Lake Erie dynamics were impacted by the wave-induced surface stress and found that it produced an enhancement of the surface mixing and a weakening of the stratification strength. It is important to note that, although the results presented in this study are consistent, there are no available measurements to 


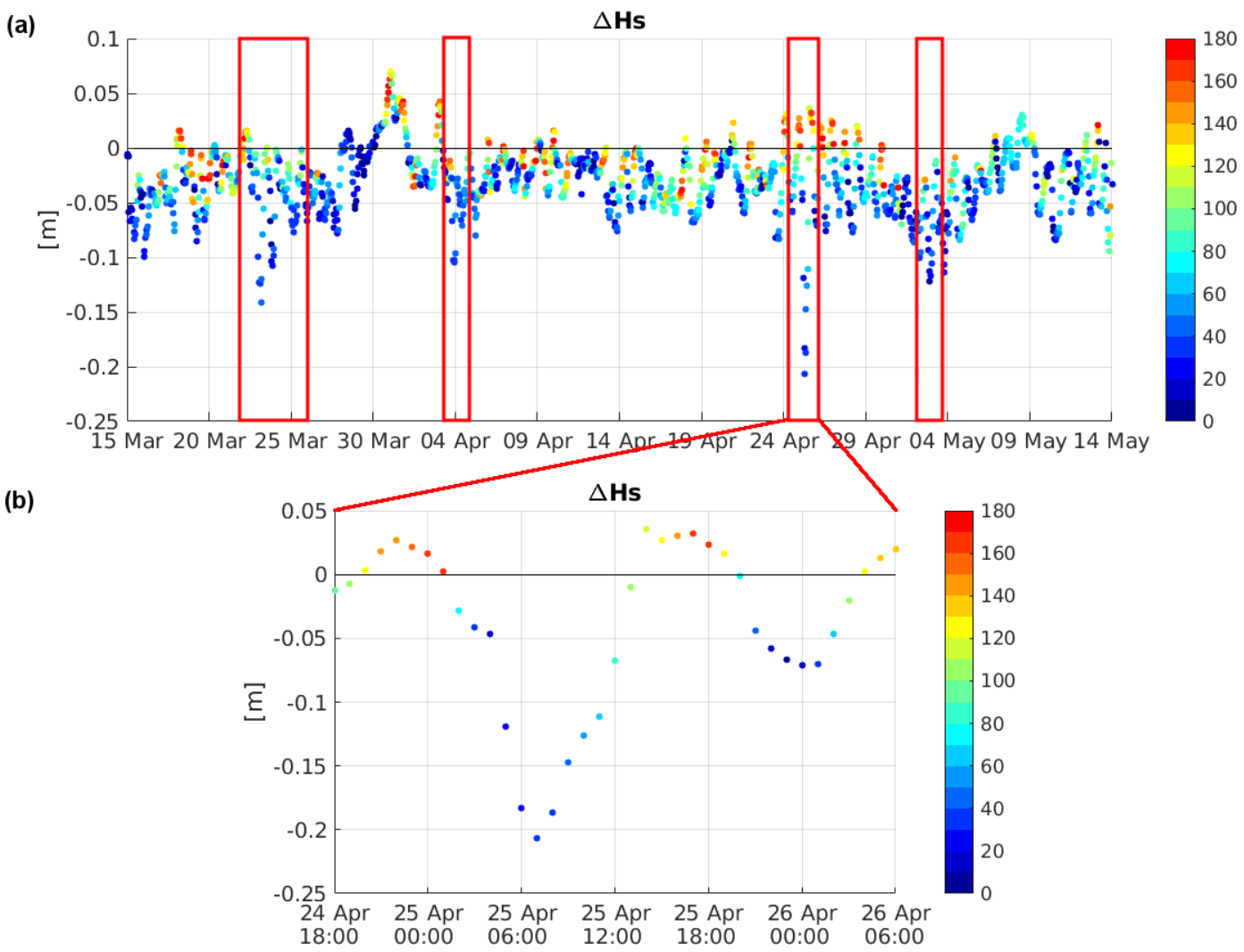

Figure 11. (a) $H s$ differences at $\mathrm{P} 2$. The different colors correspond to the angle between the directions of wave and current propagation. (b) Detailed view of the period corresponding to the E3 event.

verify them. Thus, it can not be stated if the $c R S$ run is more adjusted to the reality or if it is "overmixing".

The results presented above show that including the wave effects does not produce a relevant difference to the water current velocity during a wind-jet event and has a weak impact on the water circulation patterns. Similar results were presented by Bruneau and Toumi (2016), who analyzed the wave-induced processes in the Caspian Sea and found that they have a weak impact on the dynamics of the region. The momentum balance analysis has shown that the WF term is one of the leading terms in very shallow areas (until $\sim 50 \mathrm{~m}$ water depth). For this reason, using a numerical domain at a more coastal scale with water depths up to $50 \mathrm{~m}$ would probably show more effects at the current field, rather than the domain used in this work, which is focused on the inner shelf, where the water depth reaches values greater than $100 \mathrm{~m}$. It is important to keep in mind that the water depth in the coastal regions of our study area is very shallow and the numerical domain used in this study has very few computational points in these areas and is not able to properly solve its dynamics. As a matter of fact, Osuna and Wolf (2005) studied the WCI in the Irish Sea and found that the effect of waves on currents is evident in the eastern coastal areas (which are very shallow), with daily mean current differences larger than $10 \mathrm{~cm} \mathrm{~s}^{-1}$ during strong wave events.

\subsection{Effects of coupling on the wave field}

The numerical results presented an improvement in the $\mathrm{Tm}_{02}$ parameter when the coupling effects were considered (see Fig. 12a). Consequently, the inclusion of the current velocity in the estimation of wave period is not negligible, and it must be considered if high-quality modeling is required (similar to Bolaños et al., 2014). It should be noted that the results show that the coupling effects on the wave field are stronger for the $\mathrm{Tm}_{02}$ parameter than for the $H s$ parameter. For instance, Osuna and Monbaliu (2004) found that the effect of coupling is 1 order of magnitude stronger for the $\mathrm{Tm}_{02}$ parameter (about $20 \%$ ) than in the case of $H s$ (about $3 \%$ ).

During a wind-jet event, a decrease of the $H s$ is found when the currents are taken into account. The decrease (increase) of $H s$ in the presence of an opposite (following) current is a well-known effect that has been investigated before by several authors (e.g., Benetazzo et al., 2013; Dutour Sikirić et al., 2013; Viitak et al., 2016). For example, Benetazzo et al. (2013) studied the WCI at the semi-enclosed Gulf of Venice and found that during Bora conditions, with the currents propagating in the same direction as waves, the comparison between coupled and uncoupled models showed a reduction of $H s$ on the order of $0.6 \mathrm{~m}$ when the waves were considered. 
(a)

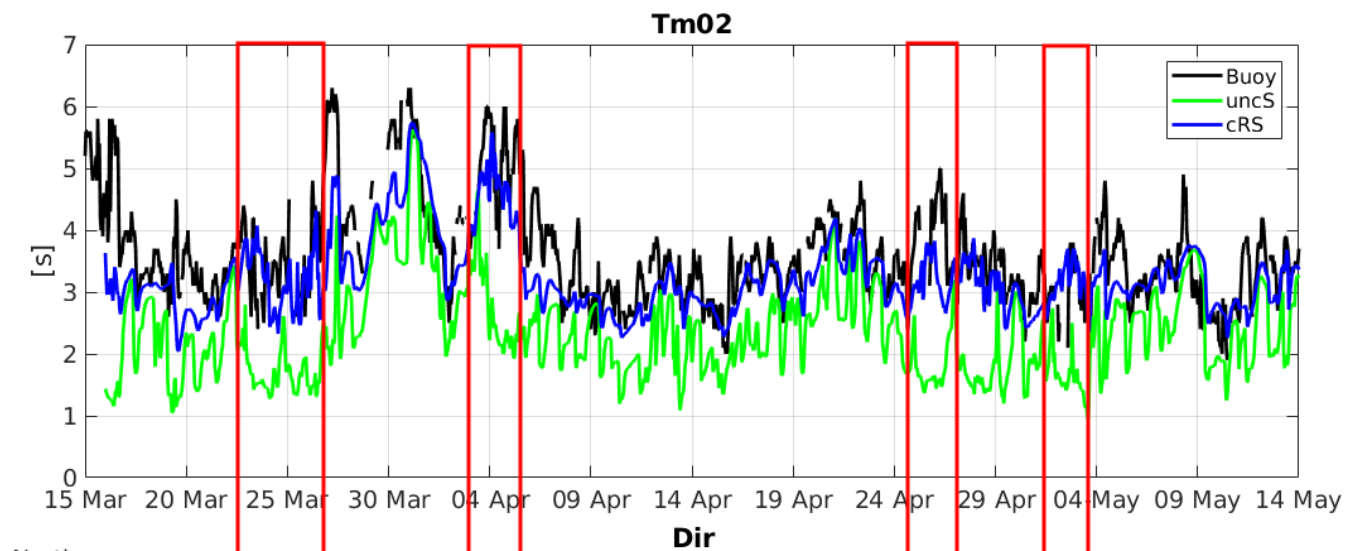

(b)

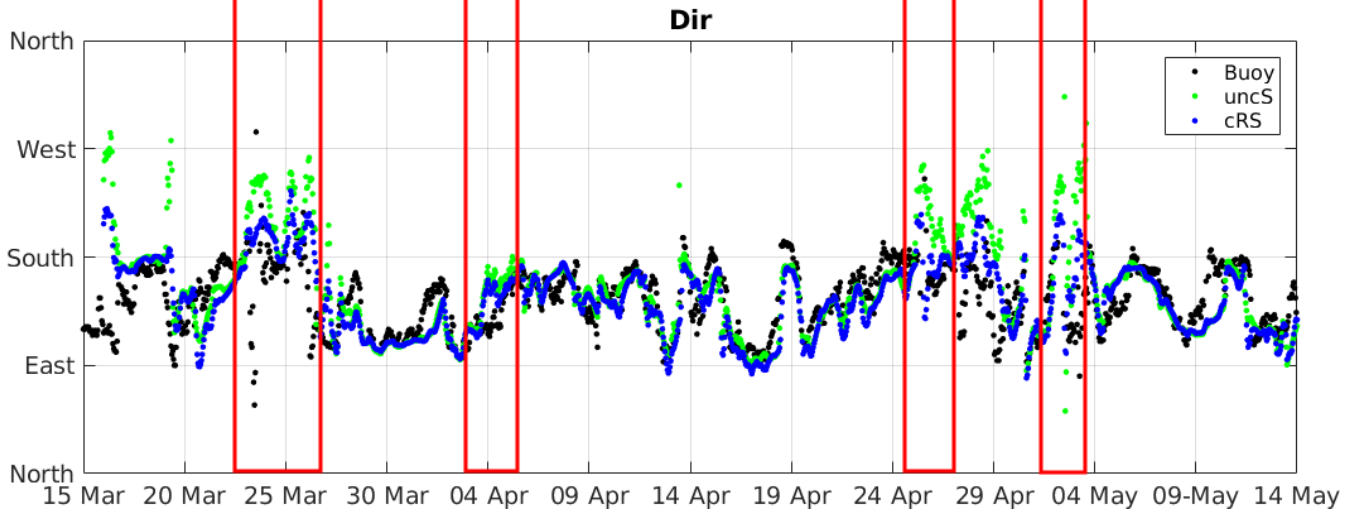

Figure 12. Comparison of the $\mathrm{Tm}_{02}$ and Dir parameters' time series obtained with the uncS (green) and $c R S$ (blue) runs with the data measured by CB (black). Note that the first $24 \mathrm{~h}$ of the model results have been rejected.

The differences in mean wave direction found in shallow waters could be due to the current-induced refraction (Wolf and Prandle, 1999; Olabarrieta et al., 2011). However, it is important to note that these differences were found very close to the coastline, specifically until $2 \mathrm{~km}$ offshore. Since the model mesh resolution is $350 \mathrm{~m}$, there are very few grid points, and thus it is not possible to extract a concise conclusion about this phenomenon with the results obtained in this study. A study at more coastal scales would be necessary to discern such processes.

Finally, considering the currents causes wave spectral reshaping. During a cross-shelf wind-jet event, the presence of currents induces a shoaling-like process. In general, a reduction of the energy peak and a slight increase of the energy at the tail of the spectrum are observed. This is consistent with the results presented in Fan et al. (2009), where the authors found that when the wave-current interactions were considered, the peak of the frequency spectrum was reduced and shifted toward higher frequency. Rusu (2010) also found that the presence of currents leads to a redistribution of the wave energy over the spectrum.

\section{Conclusions and future works}

The wave-current interactions have been investigated using numerical models. Three different runs have been performed: an uncoupled ROMS run, an uncoupled SWAN run and a two-way coupled run. The comparison among these runs shows that at the continental shelf the surface water current presents similar results in the coupled and the uncoupled configurations, and the momentum balance analysis reveals that the non-conservative WF term plays an important role in shallow waters. The results show that coupling the models results in a major mixing of the water column (the SML increase), mainly due to the TKE injection and the enhanced surface stress. Additionally, wave spectral reshaping occurs, the $\mathrm{Tm}_{02}$ improves and the wave energy (and thus the $H s$ ) diminishes (increases) when the water currents and waves propagate in the same (opposite) direction. The results also indicate that more processes occur in shallower waters, e.g., current-induced refraction, but a more coastal domain with a finer grid is necessary to evaluate them.

Overall, the numerical results are physically reasonable, as they reproduce the well known coupling effects. The results have enabled the WCIs to be investigated but more measurements would be needed in order to perform a more quantitative analysis. Thus, in the future, it would be interesting to perform some measurement campaigns to enable more ac- 
curate model validation and more exhaustive analysis of the dynamics of the region. In addition, it would be interesting to investigate the role of the sea surface roughness coupling the ROMS and SWAN models with the WRF model.

Data availability. HF radar data and buoy measurements used in this contribution can be found in http://portus.puertos.es (Spanish Government, 2018), the IBI-MFC model data are available in http:// marine.copernicus.eu (European Commission, 2018), and the WRF model data were provided by the Catalan Service of Meteorology (http://meteo.cat/, Generalitat de Catalunya, 2018). Data processing and displaying were done using a licensed Matlab program. 
Appendix A: The logarithmic wind profile

The logarithmic wind profile used to extrapolate the modeled wind from 10 to $3 \mathrm{~m}$ is as follows:

$U_{z}=\frac{U^{*}}{\kappa} \ln \left(\frac{z}{z_{0}}\right)$,

where $U_{z}$ is the mean horizontal wind velocity at a given height $z, U^{*}$ is the frictional velocity, $\kappa$ is the von Kármán constant $(\simeq 0.4)$, and $z_{0}$ is the aerodynamic roughness length.

The roughness length is estimated by means of the Charnock relation:

$z_{0}=\frac{\alpha_{\mathrm{CH}} U^{* 2}}{g}$,

where $g$ is the gravitational constant and $\alpha_{\mathrm{CH}}$ is the Charnock parameter (in this study, it has been considered an $\alpha_{\mathrm{CH}}$ equal to 0.011 ). Notice that this surface roughness formula does not necessarily coincide with the formula used in the numerical model to compute the surface stresses.

The friction velocity is related to the known wind speed at $10 \mathrm{~m}$ elevation $\left(U_{10}\right)$ with

$U^{* 2}=C_{\mathrm{D}} U_{10}^{2}$,

where $C_{\mathrm{D}}$ is the drag coefficient from $\mathrm{Wu}(1982)$ :

$C_{\mathrm{D}}\left(U_{10}\right)=\left\{\begin{array}{l}1.2875 \times 10^{-3}, \\ \text { for } U_{10}<7.5 \mathrm{~m} \mathrm{~s}^{-1} \\ \left(0.8+0.065 \times U_{10}\right) \times 10^{-3}, \\ \text { for } U_{10} \geq 7.5 \mathrm{~m} \mathrm{~s}^{-1} .\end{array}\right.$ 
Author contributions. All the authors conceived and designed the experiments and contributed ideas in the writing process. LR performed the experiments, analyzed the data and wrote the paper.

Competing interests. The authors declare that they have no conflict of interest.

Acknowledgements. The development of this research was partially funded by the Doctorats Industrials $2013 \mathrm{PhD}$ program of the Catalan Government. The authors also acknowledge Puertos del Estado for the data set provided. This work received funding from the EU H2020 program under grant agreement no. 730030 (CEASELESS project).

Edited by: John M. Huthnance

Reviewed by: two anonymous referees

\section{References}

Benetazzo, A., Carniel, S., Scalvo, M., and Bergamasco, A.: Wave-current interaction: Effect on the wave field in a semi-enclosed basin, Ocean Model., 70, 152-165, https://doi.org/10.1016/j.ocemod.2012.12.009, 2013.

Bolaños, R., Osuna, P., Wolf, J., Monbaliu, J., and Sánchez-Arcilla, A.: Development of POLCOMS-WAM model, Ocean Model., 36, 102-115, https://doi.org/10.1016/j.ocemod.2010.10.004, 2011.

Bolaños, R., Brown, J., and Souza, A.: Wave-current interactions in a tide dominated estuary, Cont. Shelf Res., 87, 109-123, https://doi.org/10.1016/j.csr.2014.05.009, 2014.

Bolaños-Sanchez, R., Sánchez-Arcilla, A., and Cateura, J.: Evaluation of two atmospheric models for wind-wave modelling in the NW Mediterranean, J. Marine Syst., 65, 336-353, https://doi.org/10.1016/j.jmarsys.2005.09.014, 2007.

Booij, N., Ris, R., and Holthuijsen, L.: A third-generation wave model for coastal regions - 1. Model description and validation, J. Geophys. Res., 104, 7649-7666, https://doi.org/10.1029/98JC02622, 1999.

Bretherton, F. and Garrett, C.: Wavetrains in Inhomogeneous Moving Media, P. Roy. Soc. A, 302, 529-554, 1968.

Bruneau, N. and Toumi, R.: A fully-coupled atmosphere-oceanwave model of the Caspian Sea, Ocean Model., 107, 97-111, https://doi.org/10.1016/j.ocemod.2016.10.006, 2016.

Cavaleri, L. and Malanotte-Rizzoli, P.: Wind wave prediction in shallow water: Theory and applications, J. Geophys. Res., 86, 961-973, https://doi.org/10.1029/JC086iC11p10961, 1981.

Dutour Sikirić, M., Roland, A., Janeković, I., Tomažić, I., and Zumić, M.: Coupling of the Regional Ocean Modeling System (ROMS) and Wind Wave Model, Ocean Model., 72, 59-73, https://doi.org/10.1016/j.ocemod.2013.08.002, 2013.

European Commission: Copernicus Marine Environment Monitoring Service, available at: http://marine.copernicus.eu, last access date: 7 February 2018.

Fairall, C., Bradley, E., Rogers, D., Edson, J., and Young, G.: Bulk parameterization of air-sea fluxes for tropical ocean-global atmosphere Coupled-Ocean Atmosphere Re- sponse Experiment, J. Geophys. Res., 101, 3747-3764, https://doi.org/10.1029/95JC03205, 1996.

Fan, Y., Ginis, I., Hara, T., Wright, C., and Walsh, E.: Numerical Simulations and Observations of Surface Wave Fields under an Extreme Tropical Cyclone, J. Phys. Oceanogr., 39, 2097-2116, https://doi.org/10.1175/2009JPO4224.1, 2009.

Font, J., Garcia-Ladona, E., and Gorriz, E.: The seasonality of mesoscale motion in the Northern Current of the western Mediterranean: several years of evidence, Oceanol. Acta, 18, 207-219, 1995.

Generalitat de Catalunya: Servei Meteorològic de Catalunya, available at: http://meteo.cat, last access date: 5 February 2018.

Grifoll, M., Garcia, V., Aretxabaleta, A., Guillén, J., Espino, M., and Warner, J.: Formation of fine sediment deposit from a flash flood river in the Mediterranean Sea, J. Geophys. Res.-Oceans, 119, 5837-5853, https://doi.org/10.1002/2014JC010187, 2014.

Grifoll, M., Aretxabaleta, A., and Espino, M.: Shelf response to intense offshore wind, J. Geophys. Res.-Oceans, 120, 6564-6580, https://doi.org/10.1002/2015JC010850, 2015.

Grifoll, M., Navarro, J., Pallares, E., Ràfols, L., Espino, M., and Palomares, A.: Ocean-atmosphere-wave characterisation of a wind jet (Ebro shelf, NW Mediterranean Sea), Nonlin. Processes Geophys., 23, 143-158, https://doi.org/10.5194/npg-23143-2016, 2016

Haidvogel, D., Arango, H., Budgell, W., Cornuelle, B., Curchitser, E., Lorenzo, E. D., Fennel, K., Geyer, W., Hermann, A., Lanerolle, L., Levin, J., McWilliams, J., Miller, A., Moore, A., Powell, T., Shchepetkin, A., Sherwood, C., Singell, R., Warner, J., and Wilkin, J.: Ocean forecasting in terrain-following coordinates: Formulation and skill assessment of the Regional Ocean Modeling System, J. Comput. Phys., 227, 3595-3624, https://doi.org/10.1016/j.jcp.2007.06.016, 2008.

Hasselmann, K., Barnett, T., Bouws, E., Carlson, H., Cartwright, D., Enke, K., Ewing, J., Gienapp, H., Hasselmann, D., Kruseman, P., Meerburg, A., Müller, P., Olbers, D., Richter, K., Sell, W., and Walden, H.: Measurements of wind-wave growth and swell decay during the Joint North Sea Wave Project (JONSWAP), Tech. Rep. 12, Deutches Hydrographisches Institut, 1973.

Hasselmann, S., Hasselmann, K., Allender, J., and Branett, T. Computations and parameterizations of the nonlinear energy transfer in a gravity wave spectrum. Part II: parameterizations of the nonlinear transfer for application in wave models., J. Phys. Oceanogr., 15, 1378-1391, https://doi.org/10.1175/15200485(1985)015<1378:CAPOTN>2.0.CO;2, 1985.

Holthuijsen, L.: Waves in Oceanic and Coastal Waters, Cambridge University Press, 2008.

Jacob, R., Larson, J., and Ong, E.: M x N Communication and Parallel Interpolation in CCSM Using the Model Coupling Toolkit, Preprint ANL/MCS-P1225-0205, Mathematics and Computer Science Division, Argonne National Laboratory, 2004.

Jenkins, A.: Wind and wave induced currents in a rotating sea with depth-varying eddy viscosity, J. Phys Oceanogr., 17, 938-951, https://doi.org/10.1175/1520 0485(1987)017<0938:WAWICI>2.0.CO;2, 1987.

Kirby, J. and Chen, T.-M.: Surface waves on vertically sheared flows: approximate dispersion relations, J. Geophys. Res., 94, 1013-1027, 1989.

Komen, G., Hasselmann, S., and Hasselmann, K.: On the existence of a fully developed wind-sea spectrum, J. Phys. 
Oceanogr., 14, 1271-1285, https://doi.org/10.1175/15200485(1984)014<1271:OTEOAF>2.0.CO;2, 1984

Kumar, N.: Measurement and Three-Dimensional Modeling of Hydrodynamic Processes In the Inner Shelf and Surf Zone, PhD thesis, University of South Carolina, 2013.

Kumar, N., Voulgaris, G., Warner, J., and Olabarrieta, M.: Implementation of the vortex force formalism in the coupled oceanatmosphere-wave-sediment transport (COAWST) modeling system for inner shelf and surf zone applications, Ocean Model., 47, 65-95, https://doi.org/10.1016/j.ocemod.2012.01.003, 2012.

Larson, J., Jacob, R., and Ong, E.: The Model Coupling Toolkit: A New Fortran90 Toolkit for Building Parallel Coupled Models, Preprint ANL/MCS-P1208-1204, Mathematics and Computer Science Division, Argonne National Laboratory, 2004.

Liang, B., Shao, Z., Wu, Y., Shi, H., and Liu, Z.: Numerical study to estimate the wave energy under Wave-Current Interaction in the Qingdao coast, China, Renew. Energ., 101, 845-855, https://doi.org/10.1016/j.renene.2016.09.015, 2017.

Lorente, P., Piedracoba, S., Soto-Navarro, J., and Alvarez-Fanjul, E.: Evaluating the surface circulation in the Ebro delta (northeastern Spain) with quality-controlled high-frequency radar measurements, Ocean Sci., 11, 921-935, https://doi.org/10.5194/os11-921-2015, 2015.

Lorente, P., Piedracoba, S., Sotillo, M., Aznar, R., AmoBalandron, A., Pascual, A., Soto-Navarro, J., and AlvarezFanjul, E.: Ocean model skill assessment in the NW Mediterranean using multi-sensor data, J. Oper. Oceanogr., 9, 75-92, https://doi.org/10.1080/1755876X.2016.1215224, 2016.

Madsen, O.: Spectral wave-current bottom boundary layer flows, in: Coastal Engineering 1994, Proceedings of the 24th International Conference on Coastal Engineering, Kobe, Japan, 384398, 1994

McWilliams, J., Restrepo, J., and Lane, E.: An asymptotic theory for the interaction of waves and currents in coastal waters, J. Fluid Mech., 511, 135-178, https://doi.org/10.1017/S0022112004009358, 2004.

Mellor, G.: The three-dimensional current and surface wave equations, J. Phys. Oceanogr. 33, 1978-1989, https://doi.org/10.1175/15200485(2003)033<1978:TTCASW>2.0.CO;2, 2003.

Mellor, G.: Some consequences of the three-dimensional current and surface wave equations, J. Phys. Oceanogr., 35, 2291-2298, https://doi.org/10.1175/JPO2794.1, 2005.

Mellor, G.: Reply, J. Phys. Oceanogr., 41, 2013-2015, https://doi.org/10.1175/JPO-D-11-071.1, 2011.

Millot, C.: Circulation in the Western Mediterranean Sea, J. Marine Syst., 20, 423-442, https://doi.org/10.1016/S09247963(98)00078-5, 1999.

Niu, Q. and Xia, M.: The role of wave-current interaction in Lake Erie's seasonal and episodic dynamics, J. Geophys. Res.-Oceans, 122, 7291-7311, https://doi.org/10.1002/2017JC012934, 2017.

O'Donncha, F., Hartnett, M., Nash, S., Ren, L., and Ragnoli, E.: Characterizing observed circulation patterns within a bay using HF radar and numerical model simulations, J. Marine Syst., 142, 96-110, https://doi.org/10.1016/j.jmarsys.2014.10.004, 2015.

Olabarrieta, M., Warner, J., and Kumar, N.: Wave-current interaction in Willapa Bay, J. Geophys. Res., 116, C12014, https://doi.org/10.1029/2011JC007387, 2011.
Osuna, P. and Monbaliu, J.: Wave-current interaction in the Southern North Sea, J. Marine Syst., 52, 65-87, https://doi.org/10.1016/j.jmarsys.2004.03.002, 2004.

Osuna, P. and Wolf, J.: A numerical study on the effect of wavecurrent interaction processes in the hydrodynamics of the Irish Sea, in: Ocean Wave Measurement and Analysis, Fifth International Symposium WAVES, Madrid, Spain, p. 93, 2005.

Port, A., Gurgel, K., and Staneva, J.: Tidal and wind-driven surface currents in the German Bight: HFR observations versus model simulations, Ocean Dynam., 61, 1567-1585, https://doi.org/10.1007/s10236-011-0412-9, 2011.

Ràfols, L., Grifoll, M., Jordà, G., Espino, M., Sairouní, A., and Bravo, M.: Shelf circulation induced by an orographic wind jet, J. Geophys. Res.-Oceans, 122, 8225-8245, https://doi.org/10.1002/2017JC012773, 2017a.

Ràfols, L., Pallares, E., Espino, M., Grifoll, M., SánchezArcilla, A., Bravo, M., and Sairouní, A.: Wind-Wave Characterization in a Wind-Jet Region: The Ebro Delta Case, Journal of Marine Science and Engineering, 5, 12, https://doi.org/10.3390/jmse5010012, 2017b.

Renault, L., Chiggiato, J., Warner, J., Gomez, M., Vizoso, G., and Tintoré, J.: Coupled atmosphere-ocean-wave simulations of a storm event over the Gulf of Lion and Balearic Sea, J. Geophys. Res., 117, C9, https://doi.org/10.1029/2012JC007924, 2012.

Rong, Z., Hetland, R., Zhang, W., and Zhang, X.: Currentwave interaction in the Mississippi-Atchafalaya river plume on the Texas-Louisiana shelf, Ocean Model., 84, 67-83, https://doi.org/10.1016/j.ocemod.2014.09.008, 2014.

Rusu, E.: Modelling of wave-current interactions at the mouths of the Danube, J. Mar. Sci. Technol., 15, 143-159, https://doi.org/10.1007/s00773-009-0078-x, 2010.

Sánchez-Arcilla, A., González-Marco, D., and Bolaños, R.: A review of wave climate and prediction along the Spanish Mediterranean coast, Nat. Hazards Earth Syst. Sci., 8, 1217-1228, https://doi.org/10.5194/nhess-8-1217-2008, 2008.

Shchepetkin, A. and McWilliams, J.: The regional oceanic modeling system (ROMS): a split-explicit, free-surface, topographyfollowing-coordinate oceanic model, Ocean Model., 9, 347-404, https://doi.org/10.1016/j.ocemod.2004.08.002, 2005.

Sheng, Y., Zhang, Y., and Paramygin, V.: Simulation of storm surge, wave, and coastal inundation in the Northeastern Gulf of Mexico region during Hurricane Ivan in 2004, Ocean Model., 35, 314 331, https://doi.org/10.1016/j.ocemod.2010.09.004, 2010.

Spanish Government: Puertos del Estado, available at: http://www. puertos.es/en-us, last access date: 6 March 2018

Svendsen, I.: Wave heights and set-up in a surf zone, Coast. Eng., 8 , 303-329, https://doi.org/10.1016/0378-3839(84)90028-0, 1984.

Svendsen, I., Haas, K., and Zhao, Q.: Quasi-3-D nearshore circulation model SHORECIRC, Center for Applied Coastal Researc, Department of Civil Engineering, University of Delaware, Newark, user's Manual, Draft Report, 2002.

Tang, C., Perrie, W., Jenkins, A., DeTracey, B., Hu, Y., Toulany, B., and Smith, P.: Observation and modeling of surface currents on the Grand Banks: a study of the wave effects on surface currents, J. Geophys. Res., 112, C10, https://doi.org/10.1029/2006JC004028, 2007.

Taylor, P. and Yelland, M.: The dependence of sea surface roughness on the height and steepness of the waves, J. 
Phys. Oceanogr., 31, 572-590, https://doi.org/10.1175/15200485(2001)031<0572:TDOSSR>2.0.CO;2, 2001.

Uchiyama, Y., McWilliams, J., and Schepetkin, A.: Wave-current interaction in an oceanic circulation model with a vortex-force formalism: Application to the surf zone, Ocean Model., 34, 1635, https://doi.org/10.1016/j.ocemod.2010.04.002, 2010.

Viitak, M., Maljutenko, I., Alari, V., Suursaar, Ü., Rikka, S., and Lagemaa, P.: The impact of surface currents and sea level on the wave field evolution during St. Jude storm in the eastern Baltic Sea, Oceanologia, 58, 176-186, https://doi.org/10.1016/j.oceano.2016.01.004, 2016.

Warner, J., Sherwood, C., Arango, H., and Signell, R.: Performance of four turbulence clousure methods implemented using a generic length scale method, Ocean Model., 8, 81-113, https://doi.org/10.1016/j.ocemod.2003.12.003, 2005.

Warner, J., Perlin, N., and Skyllingstad, E.: Using the Model Coupling Toolkit to couple earth system models, Environ. Modell. Softw., 23, 1240-1249, https://doi.org/10.1016/j.envsoft.2008.03.002, 2008a.

Warner, J., Sherwood, C., Signell, R., Harris, C., and Arango, H.: Development of a three-dimensional, regional, coupled wave, current, and sediment-transport model, Comput. Geosci., 34, 1284-1306, https://doi.org/10.1016/j.cageo.2008.02.012, 2008 b.
Warner, J., Armstrong, B., He, R., and Zambon, J.: Development of a Coupled Ocean-Atmosphere-Wave-Sediment Transport (COAWST) Modeling System, Ocean Model., 35, 230-244, https://doi.org/10.1016/j.ocemod.2010.07.010, 2010.

Willmott, C.: On the validation of models, Phys. Geogr., 2, 184 194, 1981.

Wolf, J. and Prandle, D.: Some observations of wave-current interaction, Coast. Eng., 37, 471-485, https://doi.org/10.1016/S03783839(99)00039-3, 1999.

Wu, J.: Wind-stress coefficients over sea surface from breeze to hurricane, J. Geophys. Res., 87, 9704-9706, https://doi.org/10.1029/JC087iC12p09704, 1982.

Xie, L., Wu, K., Pietrafesa, L., and Zhang, C.: A numerical study of wave-current interaction through surface and bottom stresses: Wind-driven circulation in the South Atlantic Bight under uniform winds, J. Geophys. Res., 106, 16841-16855, https://doi.org/10.1029/2000JC000292, 2001.

Xie, L., Liu, H., and Peng, M.: The effect of wave-current interactions on the storm surge and inundation in Charleston Harbor during Hurricane Hugo 1989, Ocean Model., 20, 252-269, https://doi.org/10.1016/j.ocemod.2007.10.001, 2008. 